\title{
Investigating the plasma chemistry for the synthesis of carbon nanotubes/nanofibers in an inductively coupled plasma enhanced CVD system: the effect of processing parameters
}

\author{
M Mao, A Bogaerts \\ Research Group PLASMANT, Dept. of Chemistry, University of Antwerp, \\ Universiteitsplein 1, B-2610 Antwerp, Belgium \\ Email: ming.mao@ua.ac.be
}

\begin{abstract}
.
A parameter study is carried out for an inductively coupled plasma used for the synthesis of carbon nanotubes or carbon nanofibers (CNTs/CNFs), by means of the Hybrid Plasma Equipment Model (HPEM). The influence of processing parameters including gas ratio for four different gas mixtures typically used for CNT/CNF growth (i.e., $\mathrm{CH}_{4} / \mathrm{H}_{2}, \mathrm{CH}_{4} / \mathrm{NH}_{3}, \mathrm{C}_{2} \mathrm{H}_{2} / \mathrm{H}_{2}$ and $\mathrm{C}_{2} \mathrm{H}_{2} / \mathrm{NH}_{3}$ ), ICP power (50 1000W), operating pressure (10mTorr 1Torr), bias power $(0 \sim 1000 \mathrm{~W})$ and temperature of the substrate $\left(0 \sim 1000{ }^{\circ} \mathrm{C}\right)$ on the plasma chemistry is investigated and the optimized conditions for $\mathrm{CNT} / \mathrm{CNF}$ growth are analyzed. Summarized, our calculations suggest that a lower fraction of hydrocarbon gases $\left(\mathrm{CH}_{4}\right.$ or $\mathrm{C}_{2} \mathrm{H}_{2}$, i.e., below 20\%) and hence a higher fraction of etchant gases $\left(\mathrm{H}_{2}\right.$ or $\mathrm{NH}_{3}$ ) in the gas mixture result in more "clean" conditions for controlled CNT/CNF growth. The same applies to a higher ICP power, a moderate ICP gas pressure above 100 mTorr (at least for SWCNTs), a high bias power (for aligned CNTs), and an intermediate substrate temperature.
\end{abstract}

\section{Introduction}

In the past decades, carbon nanotubes and nanofibers (CNTs/CNFs) became the subject of many investigations, encouraged by their unique electronic and mechanical properties [1]. A large number of potential applications has been considered including nanoelectronics[2], hydrogen storage[3], and field emission devices[4]. Most of these applications are, however, still under development and no significant commercial product using CNTs/CNFs can be found on the market at present[5].

CNTs/CNFs can be synthesized by several methods, such as arc discharges, laser ablation, thermal chemical vapour deposition, and plasma enhanced chemical vapour deposition (PECVD). Compared to other growth techniques, PECVD has become a very promising method because vertically aligned CNTs/CNFs can be grown at relatively low temperature. Moreover the radius and length of the CNTs/CNFs can be controlled over a wide range[6].

A variety of plasma sources have been reported in the literature for CNT/CNF growth [7-24], such as direct current (dc) glow discharges [7-10], microwave discharges (MW)[11, 12], radio-frequency capacitively coupled plasmas (RF-CCP) [13-15] and RF inductively coupled plasmas (RF-ICP)[16-24]. A wide range of operating conditions was reported for the CNT/CNF growth by PECVD. However, for a specific PECVD system, CNTs/CNFs can only be synthesized in some particular conditions. In order to investigate and optimize the suitable growth conditions, some parametric studies have been performed in the past decades.

A series of systematic studies was performed by Milne and coworkers [7-9] on the CNT growth process conditions by dc-PECVD, using a $\mathrm{C}_{2} \mathrm{H}_{2} / \mathrm{NH}_{3}$ gas mixture. The growth properties (such as growth rate, diameter, length and density of the CNTs) were studied as a function of the Ni catalyst layer thickness $(0.5 \sim 9 \mathrm{~nm})$, bias voltage $(0 \sim-600 \mathrm{~V})$, deposition temperature $\left(550 \sim 900^{\circ} \mathrm{C}\right), \mathrm{C}_{2} \mathrm{H}_{2}: \mathrm{NH}_{3}$ ratio (where the molar fraction of $\mathrm{C}_{2} \mathrm{H}_{2}$ varied from $20 \%$ to $75 \%$ ) and pressure (0.2 10Torr)[7]. They found that the diameter and length of the CNTs exhibited a linear dependence on the Ni initial thickness, while the density of the CNTs showed a maximum at $2 \mathrm{~nm}$ thickness of Ni. The electric field above the substrate 
determined the alignment of the CNTs. It was found that CNTs were perfectly aligned with uniform diameter and length at electric field $\approx 0.15 \mathrm{~V} / \mu \mathrm{m}(-600 \mathrm{~V})$. They also found that the length of the CNTs increased linearly with growth time and pressure, but showed a maximum at $30 \% \mathrm{C}_{2} \mathrm{H}_{2}$ in the $\mathrm{C}_{2} \mathrm{H}_{2}: \mathrm{NH}_{3}$ gas mixture. The study of deposition temperature showed that the growth rate initially increased with the substrate temperature and then decreased at temperatures above $700^{\circ} \mathrm{C}$ [7]. The plasma composition under the same conditions was also analyzed by mass spectrometry [8]. $\mathrm{H}_{2}, \mathrm{~N}_{2}$ and $\mathrm{HCN}$ were detected as the major neutral species beside $\mathrm{NH}_{3}$ and $\mathrm{C}_{2} \mathrm{H}_{2}$, and the dominant ions were $\mathrm{NH}_{3}{ }^{+}, \mathrm{C}_{2} \mathrm{H}_{2}{ }^{+}, \mathrm{NH}_{2}{ }^{+}, \mathrm{NH}_{4}{ }^{+}$, $\mathrm{HCN}^{+}$and $\mathrm{C}_{2} \mathrm{H}^{+}$. A variation of the fraction of $\mathrm{C}_{2} \mathrm{H}_{2}$ in the $\mathrm{C}_{2} \mathrm{H}_{2}: \mathrm{NH}_{3}$ plasma was performed in order to find out the reason why optimal growth occurred at around $20 \% \mathrm{C}_{2} \mathrm{H}_{2}$. Their results show that $\mathrm{H}_{2}$ was derived from $\mathrm{NH}_{3}$ at low $\mathrm{C}_{2} \mathrm{H}_{2}$ fraction and from $\mathrm{C}_{2} \mathrm{H}_{2}$ at high $\mathrm{C}_{2} \mathrm{H}_{2}$ fraction, which resulted in a minimum in $\mathrm{H}_{2}$ generation at around $23 \% \mathrm{C}_{2} \mathrm{H}_{2}$. The role of $\mathrm{NH}_{3}$ was found to suppress $\mathrm{C}_{2} \mathrm{H}_{2}$ decomposition and encourage CNT formation. $\mathrm{C}_{2} \mathrm{H}_{2}$ was found the dominant precursor for CNT formation. Finally, four key factors determining the properties of CNTs by dc-PECVD were also investigated by this group, including the presence of plasma during deposition, the ratio of feedstock gas to etchant gas, the plasma power and the strength of the electric field[9]. They found that the presence of plasma during the deposition process enabled deposition to take place at lower temperatures, facilitating the use of substrates which would otherwise be damaged. The ratio of carbon feedstock gas to etchant gas was important for controlling the shape of the deposited CNTs. It was also shown that a higher plasma power resulted in a lower growth rate, whereas a higher electric field caused a higher amount of ionization in the plasma, which resulted in a higher growth rate.

Hash developed a one-dimensional model to investigate the plasma chemistry for the growth of CNTs/CNFs by dc-PECVD[10]. The effect of dc power was studied in the paper. Their results showed that the plasma played a significant role in determining the gas-phase species impinging on the catalyst. It was demonstrated that the feedstock gases $\left(\mathrm{C}_{2} \mathrm{H}_{2} / \mathrm{NH}_{3}\right.$ in the case under study) were efficiently dissociated at higher plasma power, which resulted in a decrease of the growth precursor $\left(\mathrm{C}_{2} \mathrm{H}_{2}\right)$ and hence in a decreased growth rate.

The synthesis of CNTs/CNFs by MW-PECVD has been reported by several groups[11, 12]. Matthew et al.[11] carried out a parametric study of the synthesis conditions for high-quality single-walled carbon nanotubes (SWCNTs) in a MW-PECVD system. $\mathrm{A}_{2} / \mathrm{CH}_{4}$ mixture and an $\mathrm{MgO}$-supported bimetallic $\mathrm{Mo} / \mathrm{Co}$ catalyst were used in this study. Reaction parameters including temperature $\left(580 \sim 823^{\circ} \mathrm{C}\right)$, $\mathrm{H}_{2}: \mathrm{CH}_{4}$ ratio $(50: 2,50: 5,50: 10$ and 30:10), plasma power (130 500W), and synthesis time (1 180 min) were examined to assess their influence on the SWCNT growth. Significant differences between the temperature of the catalytic surface and the heated susceptor were observed. The optimum temperature was found as $770^{\circ} \mathrm{C}$ at the catalytic surface. The volumetric flow rate of hydrogen to methane was found to be optimal at a ratio of 50:10. An enhancement of the SWCNT density was observed with higher plasma power. The authors concluded that the synthesis of SWCNTs could be better controlled by these synthesis parameters in the MW-PECVD system. Wang and co-workers[12] reported a study on growing few-walled CNTs in a MW-PECVD system, where a gas mixture of $\mathrm{C}_{2} \mathrm{H}_{2} / \mathrm{NH}_{3}$ and catalyst of polystyrene-block-polyferrocenylethylmethylsilane were used. The effects of growth temperature $\left(600 \sim 885^{\circ} \mathrm{C}\right)$, growth pressure $(20 \sim 30$ Torr), and precursor gas ratio $(15 \sim 75 / 150)$ on the growth of CNTs were investigated. The study showed that the diameter of the CNTs increased when temperature decreased. Moreover, a higher growth pressure resulted in better CNT growth. Finally, it was shown that the longest CNTs with the highest density were observed for the smallest gas ratio of $\mathrm{C}_{2} \mathrm{H}_{2} / \mathrm{NH}_{3}(15 / 150)$.

Okita and co-workers performed some studies on synthesizing CNTs in an RF-CCP system. A 1D-fluid model was used to reveal the plasma chemistry behind the CNT growth[13-15], for a $\mathrm{CH}_{4} / \mathrm{H}_{2}$ gas mixture with total flux of $30 \mathrm{sccm}$, a growth pressure of $1 \sim 10 \mathrm{Torr}$, an input power of $100 \mathrm{~W}$, and the substrate heated to $650^{\circ} \mathrm{C}$. The amount of carbon deposited on the substrate was calculated both from experimental results and 1D-fluid simulations and reasonable agreement was reached[13]. It was suggested that the positive ions, as well as $\mathrm{CH}_{3}$ and $\mathrm{C}_{2} \mathrm{H}_{5}$ were the main species that fulfil the role of supplying carbon to the substrate. The effect of hydrogen on the CNT formation was investigated as well as the influence of the gas mixture ratio of $\mathrm{CH}_{4} / \mathrm{H}_{2}$ [14]. An optimal gas ratio of $27 / 3\left(\mathrm{CH}_{4} / \mathrm{H}_{2}\right)$ was found for obtaining thin CNTs with a high number density. It was confirmed that MWCNTs were not etched by a $\mathrm{H}_{2}$ plasma. The pressure dependence on the CNT growth was analyzed using a 1D-fluid model in[15]. It was found that 
non-radical neutrals heavier than $\mathrm{CH}_{4}$ were greatly generated, and their fluxes tended to increase with increasing gas pressure, while the fluxes of positive ions were decreasing. These results suggested that non-radical neutrals played an important role as CNT precursors as well as the radicals.

PECVD based on ICP systems became recently more and more attractive for the synthesis of CNTs/CNFs, because of their simple geometry, the independently controlled bias power and because they are widely used in the semiconductor industry. In order to scale up the growth conditions for CNTs/CNFs in ICP-PECVD, several parametric studies have been carried out by Meyyappan and coworkers [16-18] and by Tsai and coworkers [19-22] for different types of ICP reactors.

A detailed parametric study varying inductive power $(0 \sim 200 \mathrm{~W})$, pressure (0.5 20 Torr), temperature (700 800 ${ }^{\circ} \mathrm{C}$ ), gas composition (1 20\% of $\left.\mathrm{CH}_{4}\right)$, catalyst thickness $(1 \sim 40 \mathrm{~nm})$, and power to substrate (0 120W) was undertaken in [16-18] for a planar-type ICP-PECVD system, with the RF-coil situated on top of the reactor. $\mathrm{A} \mathrm{CH}_{4} / \mathrm{H}_{2}$ gas mixture and $\mathrm{Al} / \mathrm{Fe}$ catalysts were used to grow CNTs. Emission spectroscopy and a global model were applied to characterize the plasma under study. The results showed that both MWCNTs and MWCNFs were synthesized, and the power applied on the substrate seemed to play the key role in the transition from MWCNTs to MWCNFs. Indeed, MWCNTs were grown in the lower capacitive power region (0 20W), while MWCNFs were predominantly grown in the higher capacitive region (more than 50W). The study on dilution of argon indicated that the reduction of $\mathrm{H}$ atoms in the plasma caused the transition from MWCNF growth to MWCNT growth. The 0-D model was shown to generate global scaling laws of plasma properties with process variables, which are the main characterics of the bulk plasma. However, CNTs/CNFs are grown in the plasma sheath on the substrate surface, where the plasma properties are different from the plasma bulk; therefore a more detailed two-dimensional model will be of interest in order to describe the plasma in a more accurate way. Wei et al. [19-21] reported a parametric study on the growth of vertically aligned CNFs by a solenoidtype ICP-PECVD system. A mixture of $\mathrm{C}_{2} \mathrm{H}_{2}$ and $\mathrm{H}_{2}$ was used, where $\mathrm{C}_{2} \mathrm{H}_{2}$ provided the carbon source for the $\mathrm{CNF}$ growth, and $\mathrm{H}_{2}$ was applied to keep the Ni catalyst active. The influence of process parameters such as ICP source power $(200 \sim 1800 \mathrm{~W})$, growth time $(3 \sim 20 \mathrm{~min})$, dc bias $(-100 \sim-600 \mathrm{~V})$, pressure $\left(7.9 \sim 54\right.$ mTorr), substrate temperature $\left(400 \sim 650^{\circ} \mathrm{C}\right)$ and gas mixture ratios $\left(\mathrm{H}_{2}: \mathrm{C}_{2} \mathrm{H}_{2}\right.$ varying from 1:2 to 4:2), on the CNF formation was analyzed. The plasma composition was detected by mass spectrometry. It was shown that the CNF density decreased with ICP power, dc bias, and growth time. It was proposed that the ion-assisted etching effect by atomic hydrogen resulted in the detachment of CNFs even with low electric field in the plasma sheath.

Yang[22] studied the influence of process parameters on the synthesis of SWCNTs in an ICP-PECVD system. The gas mixture of $\mathrm{CH}_{4} / \mathrm{H}_{2}$ with two different catalysts ( $\mathrm{Fe}$ and $\mathrm{Ni}$ ) was tested. The operating pressure was fixed as 1Torr. He found that CNTs can grow both with $\mathrm{Fe}$ and Ni catalyst for the conditions under study. The substrate heating temperature affected the carbon supply to the catalyst and the diffusion of carbon on the surface and in the bulk of the catalyst. A lower substrate heating temperature was found to suppress the excess of carbon supply. It was also observed that $\mathrm{CH}_{4}$ decomposed more easily under higher ICP power to generate unsaturated hydrocarbon radicals; the latter can more easily resolve carbon for CNT growth. Therefore the author suggested that SWCNTs would be synthesized with lower ICP power.

From the literature review above, it appears that CNTs/CNFs could be synthesized under either moderate pressure (1 10 Torr) or low pressure (10s of mTorr) in a PECVD system. Both methane $\left(\mathrm{CH}_{4}\right)$ and acetylene $\left(\mathrm{C}_{2} \mathrm{H}_{2}\right)$ are popular feedstock gases for the carbon source, whereas a dilution by $\mathrm{H}_{2}$ and $\mathrm{NH}_{3}$ is often used to obtain hydrogen-rich plasmas, in order to produce 'clean' CNTs/CNFs. Most of the above works focus on how to grow CNTs/CNFs in low-temperature PECVD, whereas the role of the plasma and the key precursors for CNT growth still remain a bit unclear.

In order to obtain a good insight in the plasmas used for CNT/CNF growth, some modelling efforts have been attempted in the past decades, for DC discharges [10], CCP discharges [15] (see also above) and for ICP systems [23-24]. Denysenko et al. [23] performed detailed numerical simulations with a global model for depositing vertically aligned carbon nanostructures in an ICP-PECVD system. A gas mixture of $\mathrm{Ar} / \mathrm{CH}_{4} / \mathrm{H}_{2}$ was used in their study. The densities and fluxes of radicals and charged species as well as the effective electron temperature, and methane conversion factor were calculated under various conditions. Their results showed that the deposited cation fluxes generally exceed those of the radical neutrals. The conversion rates of methane and hydrogen were found very high ( $99 \%)$ in their study. 
Furthermore, Ostrikov et al.[24] reported a two-dimensional simulation of nanoassembly precursor species in an inductive $\mathrm{Ar} / \mathrm{H}_{2} / \mathrm{C}_{2} \mathrm{H}_{2}$ plasma. The number density and fluxes of the main building blocks and surface preparation species involved in the nanoassembly of carbon-based nanopatterns were calculated in their study. They showed that the nanopattern quality might be affected by the process parameters and the non-uniformity of the surface fluxes of each particular species.

Moreover, the growth kinetics of carbon nanotubes/nanofibers in hydrocarbon plasma have been studied by Ostrikov and coworkers[25-28]. The ion-induced dissociation of hydrocarbons, the interaction of adsorbed species with incoming hydrogen atoms, and the dissociation of hydrocarbon ions were included in the model[25-27]. They found that surface diffusion of carbon adatoms produced on the catalyst particle via ion-induced dissociation of a hydrocarbon precursor plays an important role in CNF growth at low process temperatures. The catalyst size effects on the growth of SWCNT were also analyzed in [28]. The results indicated that wide-sheath plasma systems feature growth rates up to two orders of magnitude higher than in neutral systems.

Some other models for the catalytic growth of carbon nanotubes were developed by Lysaght and Chiu(for CVD) [29-30] and by Naha and Puri[31]. The latter model is more detailed and generally applicable. It consists of several mechanisms including (a) impingement of carbon atoms from the predominant carbon-containing species in the ambient, (b) their adsorption and desorption at the catalystgaseous hydrocarbon interface, (c) surface and bulk diffusions, (d) nucleation and (e) separation of solid undissolved carbon in nanostructured form. Their results showed that an increase in either the temperature or feedstock partial pressure leads to an increasing CNT growth rate and terminal length. However, the plasma condition for CNT/CNF growth was not included in their model.

We have applied the 2D Hybrid Plasma Equipment Model (HPEM) [32-38] to investigate the plasma chemistry for a CNT-PECVD system. An ICP reactor, more specifically, a transformer coupled plasma (TCP) reactor $[16,39]$ is considered.

In a previous paper[40], the effects of different gas mixtures on the plasma chemistry for CNT/CNF growth have been studied. Four kinds of feedstock gas mixtures (i. e., $\mathrm{CH}_{4} / \mathrm{H}_{2}, \mathrm{CH}_{4} / \mathrm{NH}_{3}, \mathrm{C}_{2} \mathrm{H}_{2} / \mathrm{H}_{2}$, and $\mathrm{C}_{2} \mathrm{H}_{2} / \mathrm{NH}_{3}$ ) were considered for two different pressures: $50 \mathrm{mTorr}$ and 1 Torr, corresponding to the low and moderate pressure range investigated in the experiments.

In the present work, a detailed parametric study is carried out to investigate the effect of gas mixture ratios, ICP power, operating pressure, bias power and substrate heating temperature. Our aim is to find out the influence of these processing parameters on the plasma characteristics, especially near the surface of the substrate, used for the synthesis of CNTs/CNFs.

\section{Description of the model}

The Hybrid Plasma Equipment Model (HPEM), which has been developed at the University of Illinois by Kushner and coworkers [32-38] is used in our study. It addresses the plasma physics and chemistry in a modular way. The main modules are the Electromagnetic Module (EMM), Electron Energy Transport Module (EETM), and Fluid Kinetics Module (FKM). The EMM calculates the electromagnetic fields within a given reactor volume by solving Maxwell equations. These fields are used as inputs in the EETM, where the electron density, electron temperature, electron energy distribution function and electron impact reaction rates are computed with a Monte Carlo procedure or with the Boltzmann equation. The electron impact reaction rates are used as input in the FKM where the densities and fluxes of the various plasma species (i.e. heavy particles and electrons) are computed with continuity equations, and the electrostatic field with Poisson's equation. This electrostatic field is used as input again in the EMM, and this cycle is iterated until convergence is reached.

Four different gas mixtures, i.e., $\mathrm{CH}_{4} / \mathrm{H}_{2}, \mathrm{CH}_{4} / \mathrm{NH}_{3}, \mathrm{C}_{2} \mathrm{H}_{2} / \mathrm{H}_{2}$, and $\mathrm{C}_{2} \mathrm{H}_{2} / \mathrm{NH}_{3}$ are investigated. In the $\mathrm{CH}_{4} / \mathrm{H}_{2}$ plasma, 33 species (electrons, ions, radicals and background neutrals) along with 58 electron impact reactions, 115 ion-neutral reactions, and 45 neutral-neutral reactions are taken into account in our model. For the $\mathrm{C}_{2} \mathrm{H}_{2} / \mathrm{H}_{2}$ plasma, 48 different species are considered, which take part in 105 reactions involving 31 electron-impact reactions, 29 neutral-neutral reactions and 45 ion-neutral reactions. When $\mathrm{NH}_{3}$ is used as dilution gas instead of $\mathrm{H}_{2}$, an extra number of 22 species, 43 electron-impact reactions, 48 ion-neutral reactions and 67 neutral-neutral reactions were added to the model. All details about this plasma chemistry can be found in our previous paper[40]. 
Finally, a sticking model, where the deposition of species at the wall is described, is applied to treat the plasma-wall interactions. The sticking coefficients assumed for the different radicals can also be found in[40]. For the ions a sticking coefficient of 1 is assumed, because they will be neutralized. For the molecules, a sticking coefficient of 0 is used, as they are considered to be reflected at the walls.

It should be realized that this model does not yet provide a full description of the CNT growth, because it is limited to the plasma chemistry and does not include the actual growth processes of the CNT. Carbon drains to the CNT surface and generation of hydrogen and other fragments and their backflow are not considered. Only sticking coefficients of the various plasma species at the surface are taken into account. This might influence the plasma chemistry calculations to some extent. On the other hand, the plasma volume is much larger than the substrate surface, so that the effect on the overall plasma chemical composition is probably not so big. In a future work, we would like to include the effect of the surface processes to our plasma chemistry model, to obtain a more complete description of the PE-CVD growth process of CNTs."

\section{Results and discussion}

\subsection{Operating conditions}

The standard calculations were performed for a gas mixture of $\mathrm{CH}_{4} / \mathrm{H}_{2}$ at a pressure of $50 \mathrm{mTorr}$, in a gas ratio of $20 \% \mathrm{CH}_{4}$ and $80 \% \mathrm{H}_{2}$. Other operating conditions are: $100 \mathrm{sccm}$ total gas flow rate, $300 \mathrm{~W}$ source power, $30 \mathrm{~W}$ bias power at the substrate electrode and an operating frequency of $13.56 \mathrm{MHz}$ applied to the coil and to the substrate electrode. The substrate is heated to $550{ }^{\circ} \mathrm{C}$. These are typical

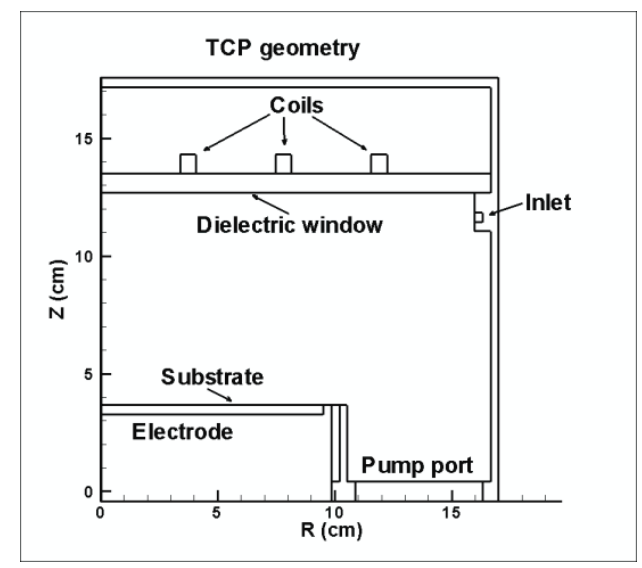

Figure 1: Two-dimensional TCP reactor geometry used in the model. The reactor is cylindrically symmetric, so only one half plane of the reactor is shown.

operating conditions for CNT growth under low pressures, as was illustrated in the introduction.

The parameter study focused on the effect of gas mixture ratios, ICP power, operating pressure, bias power and substrate heating temperature, on the plasma chemistry used for CNT/CNF growth. It should be noted that when one parameter is changed, the others are kept as the standard condition.

The reactor geometry under study is a TCP reactor, which is often used for CNT growth [11, 16, 39]. It is schematically illustrated in Figure 1.

\subsection{Effect of gas mixture ratios}

For this study, four different gas mixtures, i.e. $\mathrm{CH}_{4} / \mathrm{H}_{2}, \mathrm{CH}_{4} / \mathrm{NH}_{3}, \mathrm{C}_{2} \mathrm{H}_{2} / \mathrm{H}_{2}$ and $\mathrm{C}_{2} \mathrm{H}_{2} / \mathrm{NH}_{3}$, are taken into account, where $\mathrm{CH}_{4}$ and $\mathrm{C}_{2} \mathrm{H}_{2}$ are the deposition gases and $\mathrm{H}_{2}$ and $\mathrm{NH}_{3}$ are the etchant gases. The fraction of deposition gas $\left(\mathrm{CH}_{4}\right.$ or $\left.\mathrm{C}_{2} \mathrm{H}_{2}\right)$ in the gas mixture is varied from 0 to 100 . As it was discussed in the literature [5, 17], the carbon sources for CNT/CNF growth are determined by the species impinging on the substrate and the decomposition activity on the catalyst surface. Therefore the fluxes of different species arriving at the substrate surface were calculated at the different ratios of gas mixtures under study. 
a. Methane-hydrogen plasma $\left(\mathrm{CH}_{4} / \mathrm{H}_{2}\right)$

The calculated fluxes of the various neutrals and ions bombarding the substrate in the $\mathrm{CH}_{4} / \mathrm{H}_{2}$ mixture, averaged over the radial position on the substrate, are plotted as a function of $\mathrm{CH}_{4}$ gas fraction in figure 2. It is clear from figure 2(a) that $\mathrm{C}_{2} \mathrm{H}_{2}, \mathrm{C}_{2} \mathrm{H}_{4}$ and $\mathrm{C}_{2} \mathrm{H}_{6}$ are the dominant molecules regardless of the gas mixture ratios, besides the feedstock gases $\mathrm{CH}_{4}$ and $\mathrm{H}_{2}$. The fluxes of these molecules first increase quickly before the fraction of $\mathrm{CH}_{4}$ reaches $20 \%$, and then, more slightly when the fraction of $\mathrm{CH}_{4}$ is further enhanced. The primary radicals are $\mathrm{H}$ and $\mathrm{CH}_{3}$ at all mixture ratios. The $\mathrm{H}$ flux decreases gradually as the $\mathrm{H}_{2}$ gas fraction decreases, while the $\mathrm{CH}_{3}$ flux shows the same trend as the background gas $\mathrm{CH}_{4}$. It is also clear that the fluxes of $\mathrm{C}$ and $\mathrm{C}_{2}$ are the lowest of all radicals. These observations confirm that the carbon source for CNT/CNF growth mainly arises from the decomposition of hydrocarbon molecules on the surface of the catalyst[41].

Of course, this conclusion is only made based on the fluxes of the plasma species to the substrate, and does not take into account the surface processes, i.e., the reaction rate coefficients at the surface. Indeed, it could be that the small flux of $\mathrm{C}_{2}$ is compensated by higher reaction rates at the surface. As mentioned above, we plan to include these processes in our future work.

It is observed from figure 2(b) that most ion fluxes show a rapid decrease as the $\mathrm{CH}_{4}$ fraction increases except for $\mathrm{C}_{2} \mathrm{H}_{\mathrm{x}}{ }^{+}(\mathrm{x}=2,3,4,5,6)$. The $\mathrm{C}_{2} \mathrm{H}_{2}{ }^{+}$and $\mathrm{C}_{2} \mathrm{H}_{3}{ }^{+}$fluxes show a local maximum at $10 \% \mathrm{CH}_{4}$ gas fraction, while $\mathrm{C}_{2} \mathrm{H}_{\mathrm{x}}^{+}(\mathrm{x}=4,5,6)$ rise with increasing $\mathrm{CH}_{4}$ concentration. It is worth noting that the total ion flux decreases only slightly as a function of the $\mathrm{CH}_{4}$ fraction in the gas mixture. Moreover, because the fluxes of the heavy ions, i.e. $\mathrm{C}_{2} \mathrm{H}_{\mathrm{x}}{ }^{+}(\mathrm{x}=2 \sim 6)$, rise upon increase of the $\mathrm{CH}_{4}$ fraction, this may result in enhancement of physical sputtering and hence cause damage of the CNTs/CNFs.
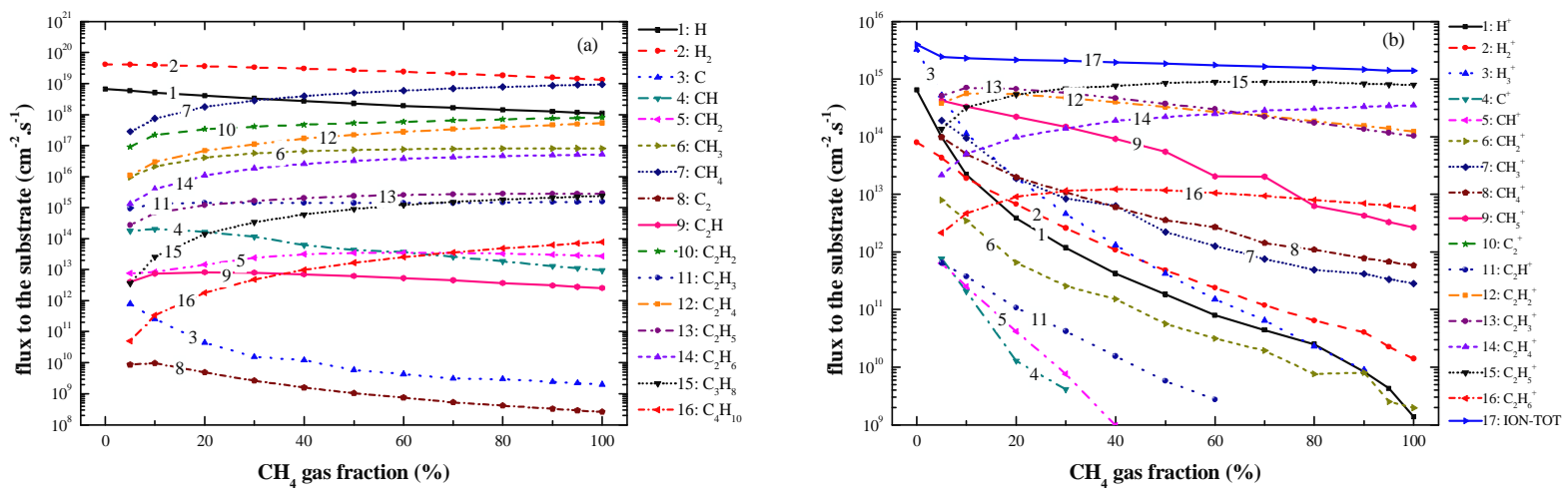

Figure 2 Calculated radially-averaged fluxes of (a) neutrals and (b) ions bombarding the substrate as a function of $\mathrm{CH}_{4}$ fraction in a $\mathrm{CH}_{4} / \mathrm{H}_{2}$ gas mixture at a pressure of $50 \mathrm{mTorr}$. The operating conditions are: $100 \mathrm{sccm}$ total gas flow rate, $300 \mathrm{~W}$ source power, $30 \mathrm{~W}$ bias power at the substrate and $13.56 \mathrm{MHz}$ operating frequency at the coil and at the substrate electrode. The substrate is heated to $550{ }^{\circ} \mathrm{C}$.

It was reported that the unsaturated hydrocarbons such as $\mathrm{C}_{2} \mathrm{H}_{2}$ and $\mathrm{C}_{2} \mathrm{H}_{4}$, have a higher reactivity than $\mathrm{CH}_{4}$ on the transition metal clusters[41]. Moreover $\mathrm{C}_{2} \mathrm{H}_{2}$ and $\mathrm{C}_{2} \mathrm{H}_{4}$ decompose more easily at the catalyst surface than $\mathrm{CH}_{4}$ at lower temperature[41]. Furthermore, $\mathrm{C}_{2} \mathrm{H}_{2}$ [42] and $\mathrm{C}_{2} \mathrm{H}_{4}$ [43] have been reported as key precursors for the efficient growth of SWCNTs by CVD. Bell et al.[8] also confirmed that $\mathrm{C}_{2} \mathrm{H}_{2}$ was the dominant precursor for CNT formation in a $\mathrm{C}_{2} \mathrm{H}_{2} / \mathrm{NH}_{3}$ plasma. Therefore it is well possible that $\mathrm{C}_{2} \mathrm{H}_{2}$ and $\mathrm{C}_{2} \mathrm{H}_{4}$ are the major precursors for CNT/CNF growth in the $\mathrm{CH}_{4} / \mathrm{H}_{2}$ plasma. The large amount of atomic hydrogen, on the other hand, plays a key role in the dehydrogenation of the adsorbed hydrocarbons, enhancing the surface diffusion of carbon, and etching amorphous carbon[41]. Finally, the $\mathrm{CH}_{3}$ radicals are probably responsible for the amorphous carbon fraction in the CNTs[13]. 


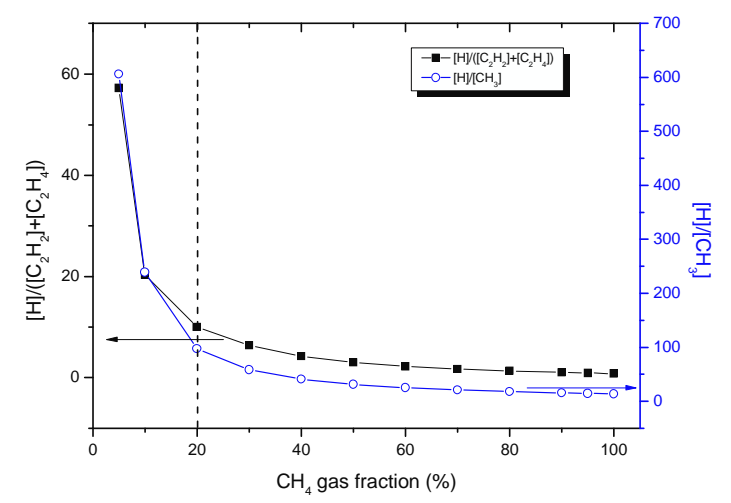

Figure 3 Ratio of etchant $(\mathrm{H})$ to the most probable carbon source for CNTs $\left(\mathrm{C}_{2} \mathrm{H}_{2}+\mathrm{C}_{2} \mathrm{H}_{4}\right)$ (left axis) and to the most probable carbon source for an amorphous film $\left(\mathrm{CH}_{3}\right)$ (right axis) as a function of $\mathrm{CH}_{4}$ gas fraction at the same operating conditions as in figure 2 .

Therefore, the ratio of $\mathrm{H}$ fluxes (representing etchants) to the fluxes of $\mathrm{C}_{2} \mathrm{H}_{2}+\mathrm{C}_{2} \mathrm{H}_{4}$ (representing the carbon supply for $\mathrm{CNTs} / \mathrm{CNFs}$ ) as well as the ratio of $\mathrm{H}$ fluxes to $\mathrm{CH}_{3}$ fluxes (as a source for amorphous carbon) are plotted in figure 3 , as a function of $\mathrm{CH}_{4}$ gas fraction. Both ratios drop rapidly at a small fraction of $\mathrm{CH}_{4}$, until about $20 \%$ of $\mathrm{CH}_{4}$, and then they further decrease slightly at high $\mathrm{CH}_{4}$ concentrations. In the left region to the dashed line, the fluxes of atomic hydrogen by far exceed the fluxes of the carbon source both for CNTs/CNFs as well as for an amorphous film. We expect that this will lead to "clean" conditions for CNT/CNF growth, as the amorphous phase, which might be present in the growing tube, will be etched away by the H-flux and moreover, the carbon supply for CNT/CNF growth is also well controlled. In [11] it was also concluded, albeit for a MW-PECVD system, that an optimal ratio of $\mathrm{H}_{2} / \mathrm{CH}_{4}$ was obtained at 50:10, hence corresponding to less than $20 \% \mathrm{CH}_{4}$ in the gas mixture.

b. Methane-ammonia plasma $\left(\mathrm{CH}_{4} / \mathrm{NH}_{3}\right)$

When $\mathrm{NH}_{3}$ is applied as the dilution gas instead of $\mathrm{H}_{2}$, some new species appear in the plasma as was mentioned in section 2 (see [40] for all details). For the sake of clarity, we define the same species both in the $\mathrm{CH}_{4} / \mathrm{H}_{2}$ plasma and in the $\mathrm{CH}_{4} / \mathrm{NH}_{3}$ plasma as "original species". The new species are called "extra species". The fluxes of the original species exhibit the same trends as in the $\mathrm{CH}_{4} / \mathrm{H}_{2}$ plasma; therefore they are not shown here again. The fluxes of the new species are displayed in figure 4 for the neutrals (a) and the ions (b).
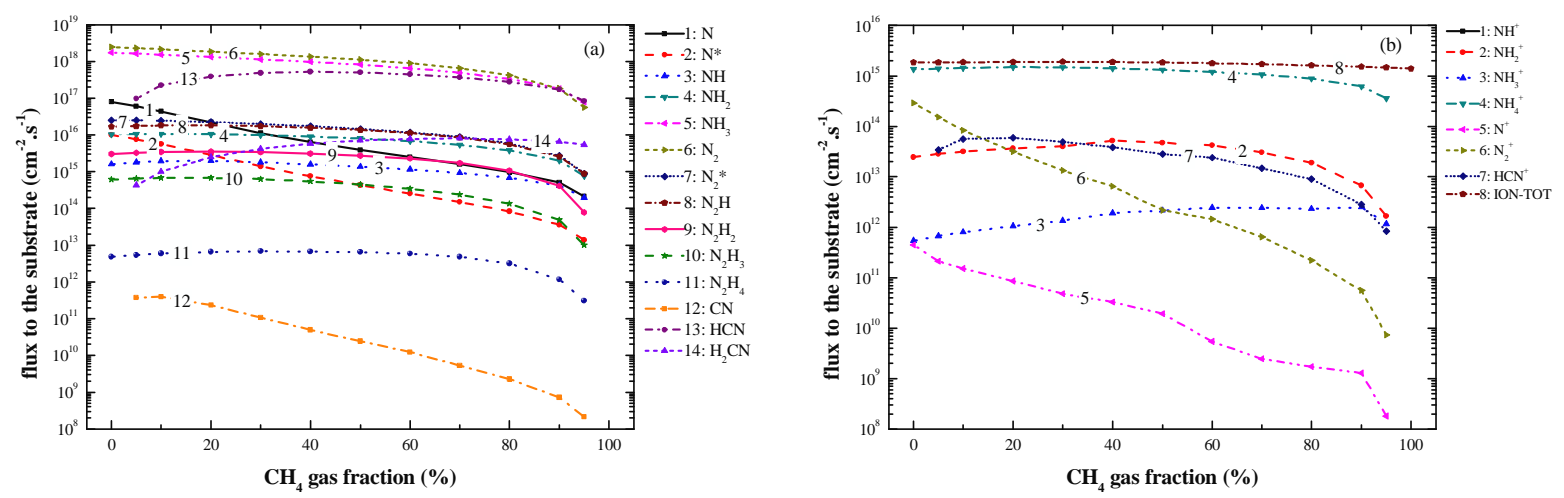

Figure 4 Calculated radially-averaged fluxes of (a) extra neutrals and (b) extra ions bombarding the substrate as a function of $\mathrm{CH}_{4}$ fraction for a $\mathrm{CH}_{4} / \mathrm{NH}_{3}$ gas mixture. The other operating conditions are the same as in figure 2.

We found that $\mathrm{H}_{2}$ is again the most dominant species, in spite of the fact that it is now not one of the feedstock gases, and it drops slightly at high fraction of $\mathrm{CH}_{4}$. Apart from the hydrocarbons $\mathrm{C}_{2} \mathrm{H}_{2}, \mathrm{C}_{2} \mathrm{H}_{4}$ and $\mathrm{C}_{2} \mathrm{H}_{6}$, now also $\mathrm{N}_{2}$ and $\mathrm{HCN}$ become predominant molecules beside the feedstock gases $\mathrm{CH}_{4}$ and $\mathrm{NH}_{3}$. With respect to the radicals, atomic hydrogen $(\mathrm{H})$ is again the most important species followed by $\mathrm{CH}_{3}, \mathrm{~N}, \mathrm{~N}_{2} \mathrm{H}$, and $\mathrm{NH}_{2}$. It is interesting that $\mathrm{H}$ and $\mathrm{H}_{2}$ follow the same trend as $\mathrm{NH}_{3}$, i.e., they drop when 
the gas fraction of $\mathrm{CH}_{4}$ increases. This indicates that $\mathrm{H}$ and $\mathrm{H}_{2}$ are mainly generated by decomposition of $\mathrm{NH}_{3}$ at the conditions under study. Also a lot of $\mathrm{HCN}$ is observed in our results, which first increases and then drops as a function of $\mathrm{CH}_{4}$ fraction. We also found that $\mathrm{HCN}$ is mainly formed in the bulk plasma region, which is consistent with Hash's results[44].

It is shown in figure 4(b), that the total ion flux again remains almost constant as a function of $\mathrm{CH}_{4}$ fraction. However, $\mathrm{NH}_{4}{ }^{+}$now become the predominant ion when $\mathrm{NH}_{3}$ is used as the additive. It is apparent that $\mathrm{NH}_{4}^{+}, \mathrm{NH}_{3}{ }^{+}$, and $\mathrm{NH}_{2}{ }^{+}$do not drop significantly, and even rise (in the case of $\mathrm{NH}_{3}{ }^{+}$) upon increase of $\mathrm{CH}_{4}$, or decrease of the $\mathrm{NH}_{3}$ fraction. This indicates that $\mathrm{NH}_{3}$ is more efficiently ionized at lower $\mathrm{NH}_{3}$ fraction. The decomposition rates (DR) of the feedstock gas molecules as a function of $\mathrm{CH}_{4}$ gas fraction in both $\mathrm{CH}_{4} / \mathrm{H}_{2}$ and $\mathrm{CH}_{4} / \mathrm{NH}_{3}$ are depicted in figure 5. Note that a DR of 1 indicates $100 \%$ decomposition.
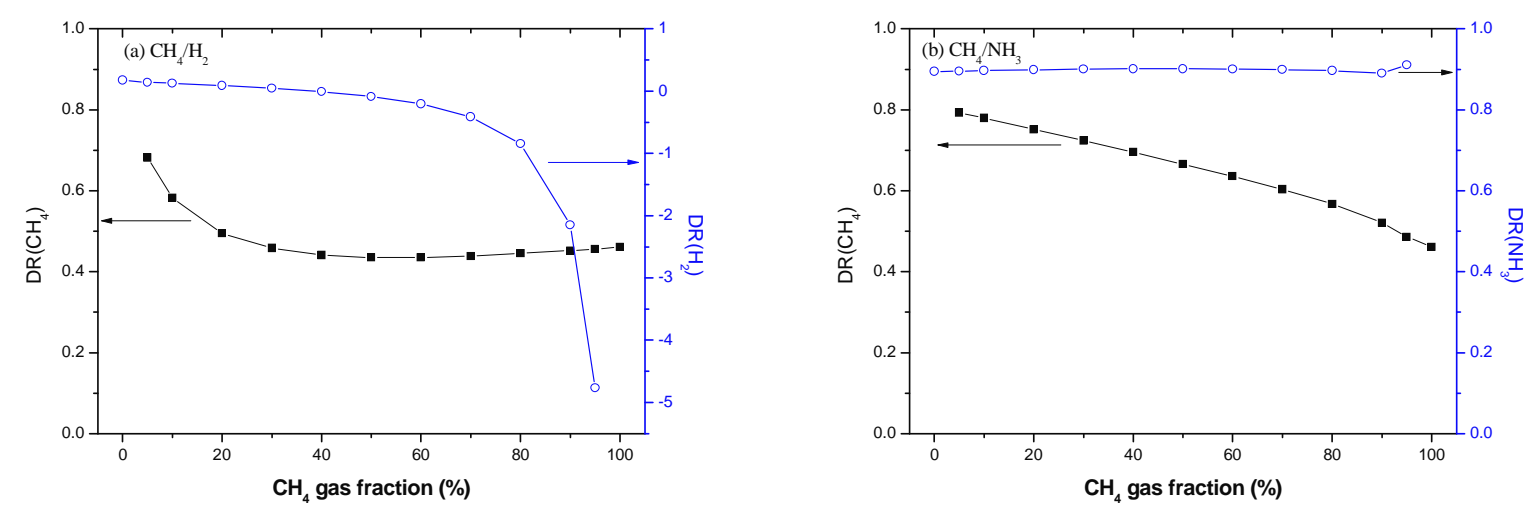

Figure 5 Decomposition rates (DR) of the background gas molecules, calculated for (a) $\mathrm{CH}_{4} / \mathrm{H}_{2}$ and (b) $\mathrm{CH}_{4} / \mathrm{NH}_{3}$ gas mixtures. The other operating conditions are the same as in figure 2. The negative values mean that more background gas species are formed instead of decomposed.

It is clear that $\mathrm{CH}_{4}$ has a higher DR at small fraction of $\mathrm{CH}_{4}$ in both gas mixtures, but it exhibits a different behavior upon increase of the $\mathrm{CH}_{4}$ gas fraction for the two different dilution gases. When a small amount of $\mathrm{H}_{2}$ is mixed into the $\mathrm{CH}_{4}$ (corresponding to a high $\mathrm{CH}_{4}$ gas fraction), the DR of $\mathrm{CH}_{4}$ decreases slightly from 0.46 at $100 \% \mathrm{CH}_{4}$ to 0.43 at $50 \% \mathrm{CH}_{4}$. For a lower fraction of $\mathrm{CH}_{4}$, and hence a higher fraction of $\mathrm{H}_{2}$, the DR of $\mathrm{CH}_{4}$ is dramatically improved up to about 0.7 at $5 \% \mathrm{CH}_{4}$. On the other hand, in the $\mathrm{CH}_{4} / \mathrm{NH}_{3}$ plasma, a linear increase is found for the $\mathrm{DR}$ of $\mathrm{CH}_{4}$ with decreasing $\mathrm{CH}_{4}$ gas fraction, from 0.46 at $100 \% \mathrm{CH}_{4}$ to about 0.8 at $5 \% \mathrm{CH}_{4}$. In general, a high DR of $\mathrm{CH}_{4}$ in the plasma at low $\mathrm{CH}_{4}$ fraction in the gas mixture points again towards favorable conditions for CNT/CNF growth, as it is stated in literature [41] that $\mathrm{CH}_{4}$ cannot decompose easily on the catalyst surface, in contrast to higher hydrocarbons.

The $\mathrm{H}_{2}$ feedstock gas hardly decomposes in the $\mathrm{CH}_{4} / \mathrm{H}_{2}$ discharge, and even much more $\mathrm{H}_{2}$ molecules are formed under $\mathrm{CH}_{4}$-rich conditions rather than decomposed. In contrast to the $\mathrm{H}_{2}$ gas, $\mathrm{NH}_{3}$ shows a very high and fairly constant DR of around 0.9 , for all gas mixture ratios. This high DR of $\mathrm{NH}_{3}$ has also been reported in the literature[10].

c. Acetylene-hydrogen plasma $\left(\mathrm{C}_{2} \mathrm{H}_{2} / \mathrm{H}_{2}\right)$

In the $\mathrm{C}_{2} \mathrm{H}_{2} / \mathrm{H}_{2}$ plasma, $\mathrm{C}_{2 \mathrm{n}} \mathrm{H}_{2}(\mathrm{n}=2,3), \mathrm{C}_{6} \mathrm{H}_{4}$ and $\mathrm{C}_{2 \mathrm{n}} \mathrm{H}_{6}(\mathrm{n}=4,5,6)$ become important molecules besides the background gases $\mathrm{C}_{2} \mathrm{H}_{2}$ and $\mathrm{H}_{2}$, as can be observed from figure 6 (a). The fluxes of $\mathrm{C}_{2 n} \mathrm{H}_{2}(\mathrm{n}=2,3)$ follow the same increasing trend as $\mathrm{C}_{2} \mathrm{H}_{2}$ upon increasing $\mathrm{C}_{2} \mathrm{H}_{2}$ gas fraction, while the $\mathrm{C}_{6} \mathrm{H}_{4}$ and $\mathrm{C}_{2 n} \mathrm{H}_{6}$ $(n=4,5,6)$ fluxes are clearly less dependent on the $\mathrm{C}_{2} \mathrm{H}_{2}$ gas fraction. This can be explained because the $\mathrm{C}_{2 \mathrm{n}} \mathrm{H}_{2}$ molecules are mainly formed by $\mathrm{C}_{2} \mathrm{H}$ insertion into $\mathrm{C}_{2 \mathrm{n}-2} \mathrm{H}_{2}(\mathrm{n}=2,3)$, which results in similar trends of the $\mathrm{C}_{2 \mathrm{n}} \mathrm{H}_{2}(\mathrm{n}=1,2,3)$ fluxes. However, the $\mathrm{C}_{6} \mathrm{H}_{4}$ and $\mathrm{C}_{2 \mathrm{n}} \mathrm{H}_{6}(\mathrm{n}=4,5,6)$ species are formed by neutralization of the corresponding ions on the wall, and they stay in the reactor much longer due to their heavy mass.

The primary radicals (see figure $6(b))$ are $\mathrm{H}$ and $\mathrm{C}_{2 \mathrm{n}} \mathrm{H}_{3}(\mathrm{n}=1,2,3)$. The $\mathrm{H}$ flux drops linearly upon increase of the $\mathrm{C}_{2} \mathrm{H}_{2}$ fraction (and hence decrease of the $\mathrm{H}_{2}$ fraction), while the fluxes of $\mathrm{C}_{2 n} \mathrm{H}_{3}(\mathrm{n}=1,2$, 3) species rise gradually with the $\mathrm{C}_{2} \mathrm{H}_{2}$ fraction and reach a maximum at around $40 \% \mathrm{C}_{2} \mathrm{H}_{2}$. When the $\mathrm{C}_{2} \mathrm{H}_{2}$ fraction further increases, the fluxes of $\mathrm{C}_{2 n} \mathrm{H}_{3}(\mathrm{n}=1,2,3)$ species begin to drop. This is because the 
$\mathrm{C}_{2 \mathrm{n}} \mathrm{H}_{3}(\mathrm{n}=1,2,3)$ radicals are mainly formed by $\mathrm{H}$ insertion into $\mathrm{C}_{2 \mathrm{n}} \mathrm{H}_{2}(\mathrm{n}=1,2,3)$, and the significant decrease of the $\mathrm{H}$ radicals with increasing $\mathrm{C}_{2} \mathrm{H}_{2}$ fraction should be responsible for this.

From figure 6(c), it is clear that the total ion flux shows a steady downward trend with increase of $\mathrm{C}_{2} \mathrm{H}_{2}$ gas fraction. Indeed, a large number of heavy ions such as $\mathrm{C}_{2 \mathrm{n}} \mathrm{H}_{6}{ }^{+}(\mathrm{n}=4,5,6)$ are formed in the $\mathrm{C}_{2} \mathrm{H}_{2}$ plasma, which become predominant with increase of the $\mathrm{C}_{2} \mathrm{H}_{2}$ fraction. The lower mobility of these heavy ions compared to light ions results in the decrease of total ion flux bombarding the substrate.

Similar to the $\mathrm{CH}_{4} / \mathrm{H}_{2}$ discharge, the lighter ions such as $\mathrm{H}^{+}, \mathrm{H}_{2}{ }^{+}, \mathrm{C}_{2} \mathrm{H}_{2}{ }^{+}$and $\mathrm{C}_{2} \mathrm{H}_{3}{ }^{+}$are predominant under $\mathrm{H}_{2}$-rich conditions, while the heavier ions (i.e., $\mathrm{C}_{10} \mathrm{H}_{6}{ }^{+}$and $\mathrm{C}_{12} \mathrm{H}_{6}{ }^{+}$) turn to be important under $\mathrm{C}_{2} \mathrm{H}_{2}$-rich conditions. It is worth noting that a large flux of $\mathrm{C}_{4} \mathrm{H}_{3}{ }^{+}$(see figure 6(d)) was observed for all conditions. Therefore this ion is suggested to play an important role in the growth of CNTs/CNFs, for the conditions under study.
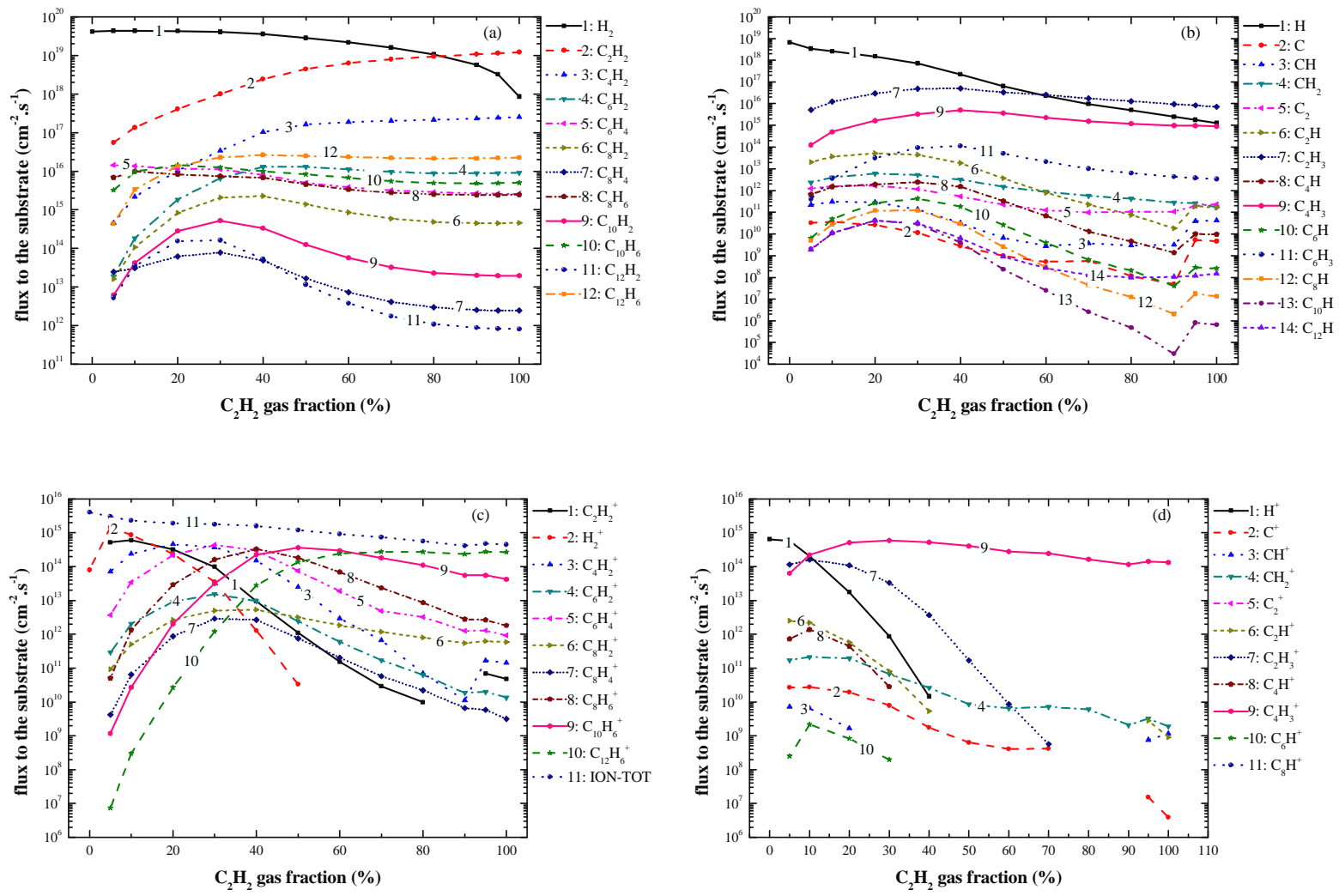

Figure 6 Calculated radially-averaged fluxes of $(a, b)$ neutrals and $(c, d)$ ions bombarding the substrate as a function of $\mathrm{C}_{2} \mathrm{H}_{2}$ gas fraction for a $\mathrm{C}_{2} \mathrm{H}_{2} / \mathrm{H}_{2}$ gas mixture. The other operating conditions are the same as in figure 2 .

It is stated that hydrocarbon ions play a key role in the formation of amorphous carbon films[45]. At conditions with low $\mathrm{C}_{2} \mathrm{H}_{2}$ fraction, most hydrocarbon ions show a relatively low flux as is clear from figure $6(\mathrm{c}, \mathrm{d})$, which would efficiently suppress the amorphous carbon growth. This could explain why "clean" CNTs/CNFs are typically grown under $\mathrm{H}_{2}$-rich conditions $[8,20]$. Indeed, it was observed that the CNF growth rate decreased while the amorphous carbon film deposition increased with rising $\mathrm{C}_{2} \mathrm{H}_{2}$ fraction, both in a $\mathrm{C}_{2} \mathrm{H}_{2} / \mathrm{H}_{2}$ mixture[20] and in a $\mathrm{C}_{2} \mathrm{H}_{2} / \mathrm{NH}_{3}$ mixture[8].

d. Acetylene-ammonia plasma $\left(\mathrm{C}_{2} \mathrm{H}_{2} / \mathrm{NH}_{3}\right)$

When $\mathrm{NH}_{3}$ is used as the dilution gas (see figure 7), $\mathrm{N}_{2}, \mathrm{~N}_{2} \mathrm{H}_{2}$ and $\mathrm{NH}_{4}{ }^{+}$are found to be dominant neutrals and ions, respectively, similar to the $\mathrm{CH}_{4} / \mathrm{NH}_{3}$ plasma. Similar observations were made in [8]. The species $\mathrm{N}_{2} \mathrm{H}$ and $\mathrm{NH}_{2}$ become very important (see figure 7 (a)). However, unlike in the $\mathrm{CH}_{4} / \mathrm{NH}_{3}$ plasma, the flux of $\mathrm{HCN}$ is not significant at all. This is because $\mathrm{HCN}$ is generated from the reaction between $\mathrm{CH}_{\mathrm{x}}(\mathrm{x}=2,3,4)$ and $\mathrm{N}$ atoms, and the lower density of $\mathrm{CH}_{\mathrm{x}}(\mathrm{x}=2,3,4)$ in the $\mathrm{C}_{2} \mathrm{H}_{2}$ plasma leads to a lower formation of HCN. It was reported[46] that the presence of $\mathrm{N}_{2}$ can enhance carbon diffusion into the catalysts. Indeed, the bombardment energy of ions in a nitrogen plasma is greater than 
in a hydrogen plasma, which can keep the front catalyst surface clean and actively prolong surface passivation to enhance carbon bulk diffusion[46]. Our results show that the $\mathrm{N}_{2}$ flux is predominant beside the $\mathrm{NH}_{3}$ flux, especially for a low $\mathrm{C}_{2} \mathrm{H}_{2}$ fraction(less than 20\%). Hence, this might explain why in many papers $[7-9,12]$ the $\mathrm{C}_{2} \mathrm{H}_{2} / \mathrm{NH}_{3}$ mixture is used for CNT/CNF growth rather than the $\mathrm{C}_{2} \mathrm{H}_{2} / \mathrm{H}_{2}$ plasma.
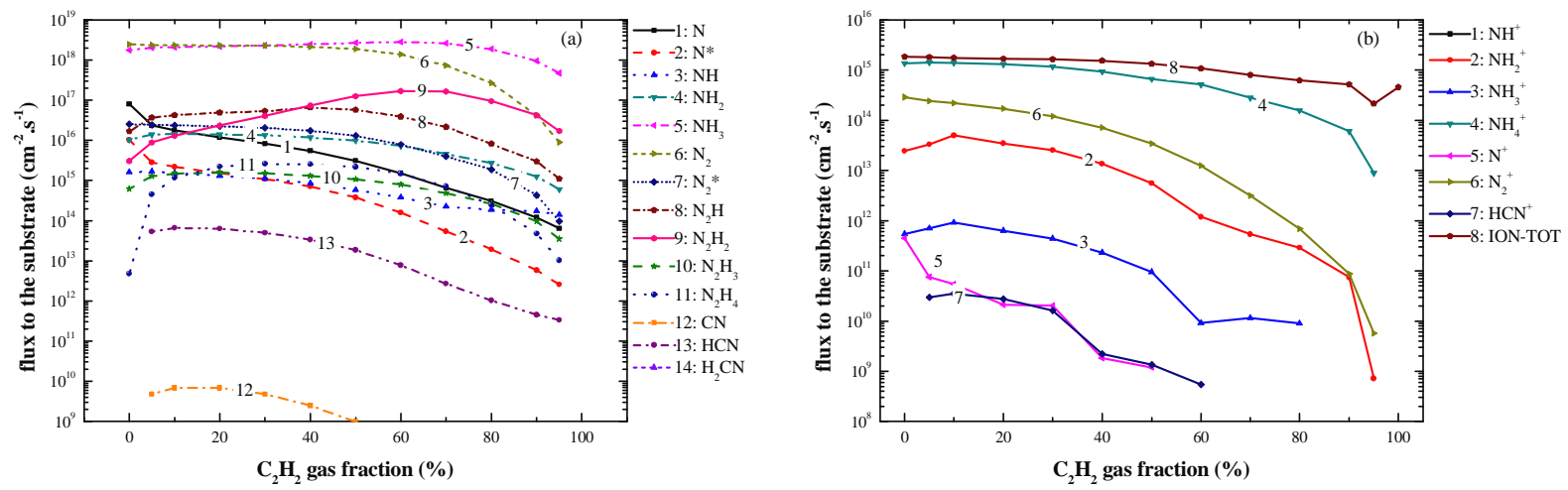

Figure 7 Calculated radially-averaged fluxes of (a) extra neutrals and (b) extra ions bombarding the substrate as a function of $\mathrm{C}_{2} \mathrm{H}_{2}$ gas fraction for a $\mathrm{C}_{2} \mathrm{H}_{2} / \mathrm{NH}_{3}$ gas mixture. The other operating conditions are the same as in figure 2.

The DRs of the background gas molecules in the $\mathrm{C}_{2} \mathrm{H}_{2}$-containing plasmas are displayed in figure 8 (a) for the $\mathrm{C}_{2} \mathrm{H}_{2} / \mathrm{H}_{2}$ plasma and in figure 8 (b) for the $\mathrm{C}_{2} \mathrm{H}_{2} / \mathrm{NH}_{3}$ plasma. It is clear that $\mathrm{C}_{2} \mathrm{H}_{2}$ has a quite high DR (more than 0.75) when the gas fraction of $\mathrm{C}_{2} \mathrm{H}_{2}$ in the mixture is less than $30 \%$. Such high DR of $\mathrm{C}_{2} \mathrm{H}_{2}$ leads to the reduction of $\mathrm{C}_{2} \mathrm{H}_{2}$ in the bulk plasma, and hence lowers the $\mathrm{C}_{2} \mathrm{H}_{2}$ flux arriving at the substrate. This might result in a relatively low growth rate of CNTs/CNFs, which was indeed observed in [7, 21], because the $\mathrm{C}_{2} \mathrm{H}_{2}$ species are believed to be the main precursors for CNT/CNF formation in a PECVD system $[8,47]$. When the gas fraction of $\mathrm{C}_{2} \mathrm{H}_{2}$ is in the range of $30 \%$ to $70 \%$, a rapid drop is observed for the DR of $\mathrm{C}_{2} \mathrm{H}_{2}$ (from 0.75 to around 0.2 ). In this region, the carbon supply for CNT/CNF growth rapidly becomes greater for two reasons: (i) the percentage of $\mathrm{C}_{2} \mathrm{H}_{2}$ in the mixture increases and (ii) the DR of $\mathrm{C}_{2} \mathrm{H}_{2}$ decreases. When the gas fraction of $\mathrm{C}_{2} \mathrm{H}_{2}$ is further increased, the $\mathrm{C}_{2} \mathrm{H}_{2}$ gas molecules are hardly decomposed in the plasma.
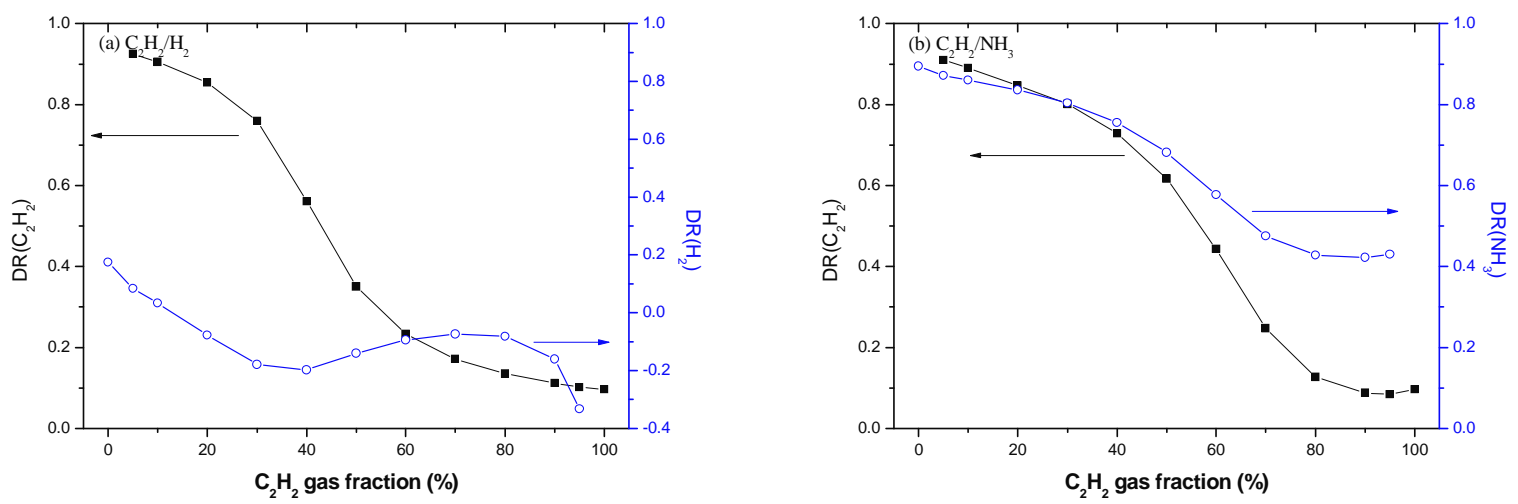

Figure 8 Decomposition rates (DR) of the background gas molecules, calculated for (a) $\mathrm{C}_{2} \mathrm{H}_{2} / \mathrm{H}_{2}$ and (b) $\mathrm{C}_{2} \mathrm{H}_{2} / \mathrm{NH}_{3}$ gas mixtures. The other operating conditions are the same as in figure 2. The negative values mean that more background gas species are formed instead of decomposed.

It is also observed that $\mathrm{H}_{2}$ shows a very low DR at high fraction of $\mathrm{H}_{2}$ in the mixture (see figure 8(a)). Furthermore, negative values of the DR are observed at $\mathrm{C}_{2} \mathrm{H}_{2}$-rich conditions. Different from the $\mathrm{H}_{2}$ gas additive, the DR of $\mathrm{NH}_{3}$ shows a similar trend as the $\mathrm{C}_{2} \mathrm{H}_{2}$ DR. Indeed, the DR of $\mathrm{NH}_{3}$ decreases with increasing $\mathrm{C}_{2} \mathrm{H}_{2}$ gas fraction, which leads to a decline of the atomic hydrogen at high fraction of $\mathrm{C}_{2} \mathrm{H}_{2}$. Moreover, the excess of heavy hydrocarbon ions is also found in this region. Therefore, we expect that an amorphous carbon film will be formed, which cannot easily be etched away because of the low amount of etching $\mathrm{H}$ atoms, and this will suppress the growth of CNTs/CNFs. Indeed, most experiments in the literature were performed at $\mathrm{C}_{2} \mathrm{H}_{2}$ fraction below $20 \%$ [7, 12]. The influence of the $\mathrm{C}_{2} \mathrm{H}_{2}: \mathrm{NH}_{3}$ ratio on the structure of CNTs synthesized by dc-PECVD has been reported by Chhowalla et al. [7]. They found that 
CNTs could be formed for $\mathrm{C}_{2} \mathrm{H}_{2}$ fraction from $5 \%$ to $30 \%$. Above $30 \% \mathrm{C}_{2} \mathrm{H}_{2}$, the CNTs became obelisklike and then turned to a tip structure with even higher $\mathrm{C}_{2} \mathrm{H}_{2}$ fraction. Also in [12] for a MW-PECVD system, the longest CNTs with the highest density were obtained for the smallest $\mathrm{C}_{2} \mathrm{H}_{2} / \mathrm{NH}_{3}$ gas ratio (15/150), corresponding to around $10 \%$ of $\mathrm{C}_{2} \mathrm{H}_{2}$.

In the following sections, the effects of ICP power, operating pressure, bias power and substrate heating temperature on the plasma chemistry for CNT/CNF growth will be analyzed, considering only the $\mathrm{CH}_{4} / \mathrm{H}_{2}$ gas mixture.

\subsection{Effect of ICP power}

The fluxes of species on the substrate as a function of ICP power are plotted in figure 9(a) for the neutrals and in figure 9(b) for the ions. A higher ICP power will give rise to increased dissociation and ionization of the molecules, which results in a decreasing flux of the molecules $\left(\mathrm{CH}_{4}, \mathrm{C}_{2} \mathrm{H}_{2}, \mathrm{C}_{2} \mathrm{H}_{4}, \mathrm{C}_{2} \mathrm{H}_{6}, \mathrm{C}_{3} \mathrm{H}_{8}\right.$, and $\left.\mathrm{C}_{4} \mathrm{H}_{10}\right)$, and an increase in the fluxes of lighter radicals $\left(\mathrm{H}, \mathrm{CH}, \mathrm{C}\right.$, and $\left.\mathrm{C}_{2}\right)$ and ions. Consequently the drop of $\mathrm{C}_{2} \mathrm{H}_{2}$ and $\mathrm{CH}_{3}$ will result in a reduction of carbon supply for the growth of CNTs/CNFs, on the one hand, and amorphous carbon film, on the other hand. In addition, the increase of $\mathrm{H}$ radicals will enhance the removal of amorphous carbon film.
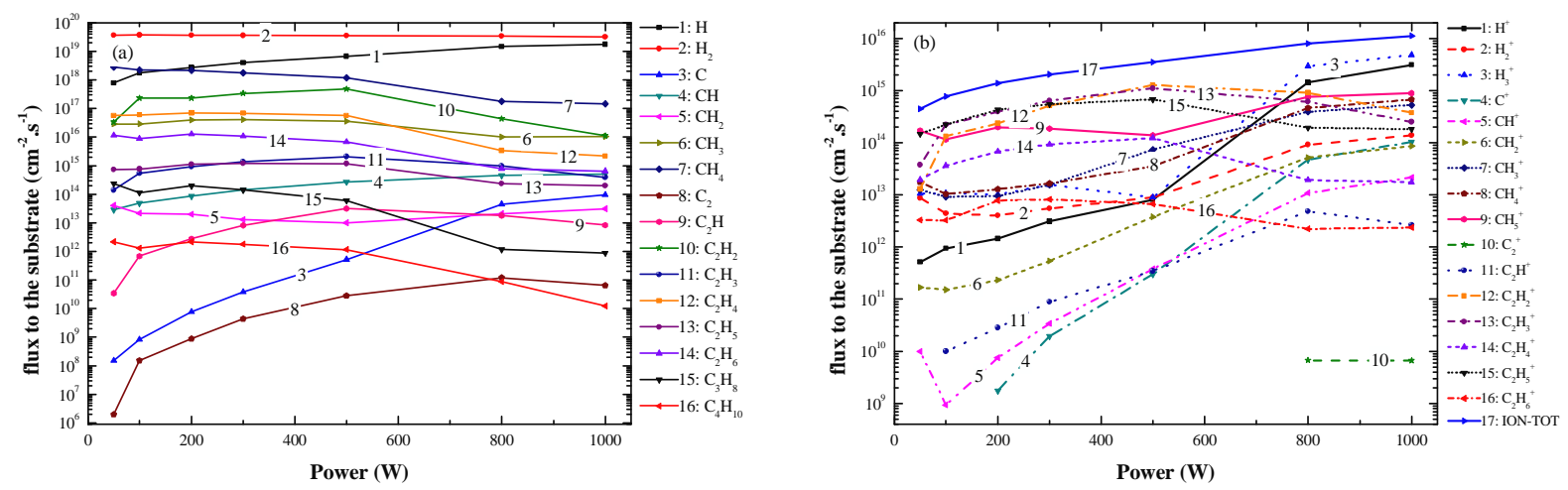

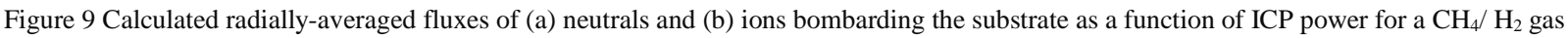
mixture at a pressure of 50 mTorr with gas ratio of 20:80. The other operating conditions are the same as in figure 2 .

It is indeed observed from figure 10 that the ratio of etchant $(\mathrm{H})$ to depositing carbon sources both for CNTs $\left(\mathrm{C}_{2} \mathrm{H}_{2}+\mathrm{C}_{2} \mathrm{H}_{4}\right)$ and for an amorphous carbon film $\left(\mathrm{CH}_{3}\right)$ increases drastically when the ICP power is enhanced from $500 \mathrm{~W}$ to $1000 \mathrm{~W}$. This indicates that the etching effect by atomic hydrogen is significant in the high ICP power region. Therefore, this suggests that a relatively "clean" condition for the formation of CNTs/CNFs could be achieved at higher ICP power, which is indeed reported by Lin $e t$ al.[20]. Indeed, they found that more amorphous carbon film was deposited on the surface of the CNFs and the substrate for $250 \mathrm{~W}$ ICP power than in the 750W case [20].

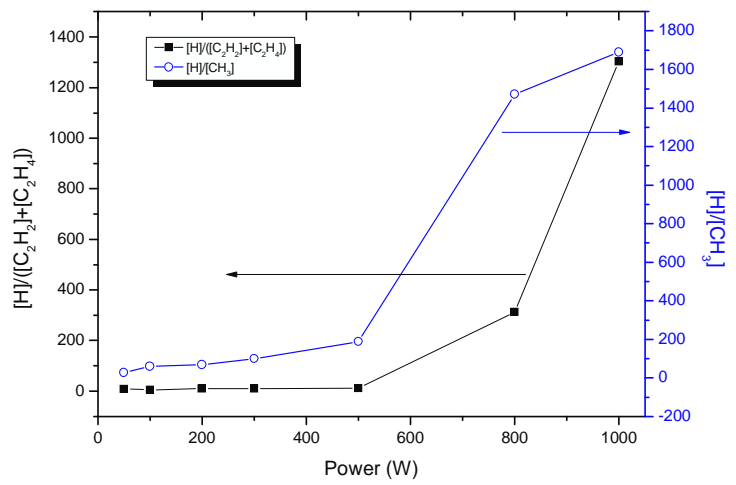

Figure 10 Ratio of etchant $(\mathrm{H})$ to the carbon source for $\mathrm{CNTs}\left(\mathrm{C}_{2} \mathrm{H}_{2}+\mathrm{C}_{2} \mathrm{H}_{4}\right)$ and for an amorphous carbon film $\left(\mathrm{CH}_{3}\right)$ as a function of ICP power for the $\mathrm{CH}_{4} / \mathrm{H}_{2}$ mixture at the same operating conditions as in figure 9 . 
The influence of ICP power on the DR of the background gas molecules is displayed in figure 11. Both DRs rise nearly linearly with ICP power for the reason explained above. The DR of $\mathrm{CH}_{4}$ is around 0.2 at $50 \mathrm{~W}$ and increases to almost 0.96 at $1000 \mathrm{~W}$. Again, this suggests that a higher ICP power is beneficial for $\mathrm{CNT} / \mathrm{CNF}$ growth, as the $\mathrm{CH}_{4}$ molecules do not efficiently decompose at the catalyst surface; therefore the decomposition needs to take place already in the plasma. The DR of $\mathrm{H}_{2}$ is only 0.05 at $50 \mathrm{~W}$ and increases to 0.22 at $1000 \mathrm{~W}$. Although the DR of $\mathrm{H}_{2}$ becomes higher at $1000 \mathrm{~W}$, almost no change was observed for the flux of $\mathrm{H}_{2}$ on the substrate, because the loss of $\mathrm{H}_{2}$ caused by decomposition is compensated by new $\mathrm{H}_{2}$ created by decomposition of $\mathrm{CH}_{4}$.

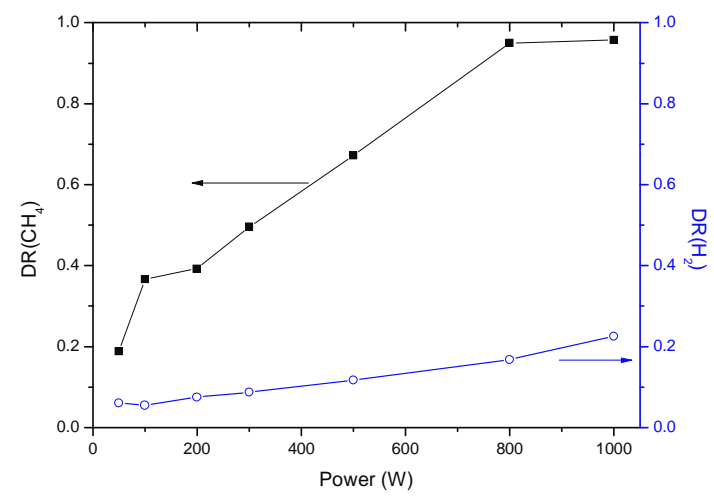

Figure 11 Decomposition rates (DR) of the background gas molecules, calculated for the $\mathrm{CH}_{4} / \mathrm{H}_{2}$ gas mixture as a function of the ICP power. The other operating conditions are the same as in figure 9.

\subsection{Effect of gas pressure}

The fluxes of the different neutral species to the substrate as a function of pressure are plotted in figure 12. It is found that the feedstock gases $\mathrm{H}_{2}$ and $\mathrm{CH}_{4}$ increase with pressure as expected, while the radicals $\mathrm{C}, \mathrm{CH}, \mathrm{CH}_{2}, \mathrm{C}_{2}, \mathrm{C}_{2} \mathrm{H}$ and $\mathrm{C}_{2} \mathrm{H}_{3}$ decrease at higher pressure. The other neutrals remain virtually unchanged. As was illustrated in [40], most of the ion fluxes drop at increasing pressure; hence the total ion flux also shows a decreasing trend as a function of pressure. This is because the electrons lose their energy faster at higher pressure, which leads to a decrease of ionization, and hence results in a drop of the ion fluxes with increasing pressure.

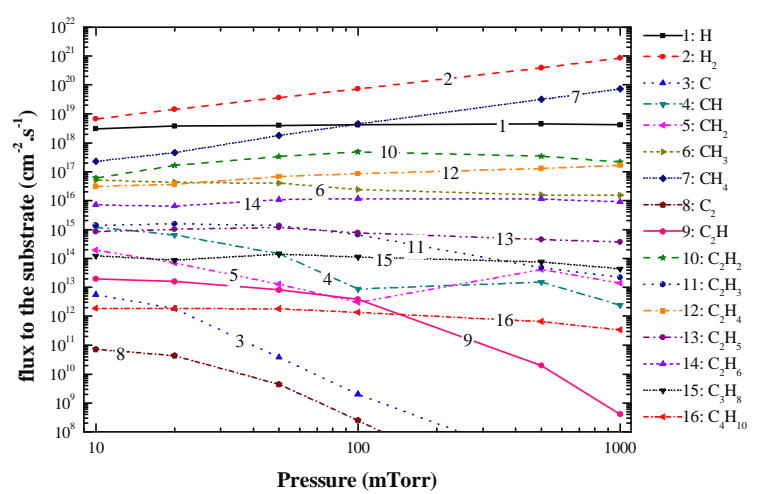

Figure 12 Calculated radially-averaged fluxes of the various neutrals bombarding the substrate as a function of gas pressure for a $\mathrm{CH}_{4} / \mathrm{H}_{2}$ gas mixture with gas ratio of 20:80. The other operating conditions are the same as in figure 2.

The ratios of etching species $(\mathrm{H})$ to the carbon source for CNTs $\left(\mathrm{C}_{2} \mathrm{H}_{2}+\mathrm{C}_{2} \mathrm{H}_{4}\right)$ and to the carbon source for an amorphous carbon film $\left(\mathrm{CH}_{3}\right)$ are plotted in figure 13. It is clear that a larger ratio of $\mathrm{H}$ flux to $\mathrm{CH}_{3}$ flux is found at high pressure, while the ratio of $\mathrm{H}$ flux to $\mathrm{C}_{2} \mathrm{H}_{2}$ and $\mathrm{C}_{2} \mathrm{H}_{4}$ drops dramatically first and then levels off at 100 mTorr. This indicates that CNTs/CNFs could be synthesized with less amorphous carbon pollution at higher pressure. In addition, the lower $\mathrm{DR}$ of $\mathrm{CH}_{4}$ at higher pressure, as illustrated in figure 14, implies that the carbon supply for CNTs/CNFs could be limited at higher pressure. This could explain why SWCNTs are always synthesized at higher pressures (i.e., in the order of 1 Torr) by an ICPPECVD system, as reported in[22], where the carbon source for growth can be well controlled. 


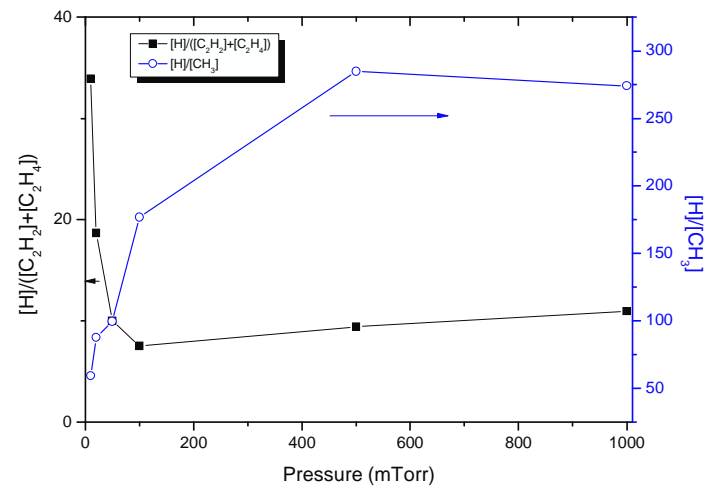

Figure 13 Ratio of etchant species $(\mathrm{H})$ to the carbon source for CNTs $\left(\mathrm{C}_{2} \mathrm{H}_{2}+\mathrm{C}_{2} \mathrm{H}_{4}\right)$ and to the carbon source for an amorphous film $\left(\mathrm{CH}_{3}\right)$ as a function of gas pressure at the same operating conditions as in figure 12 .

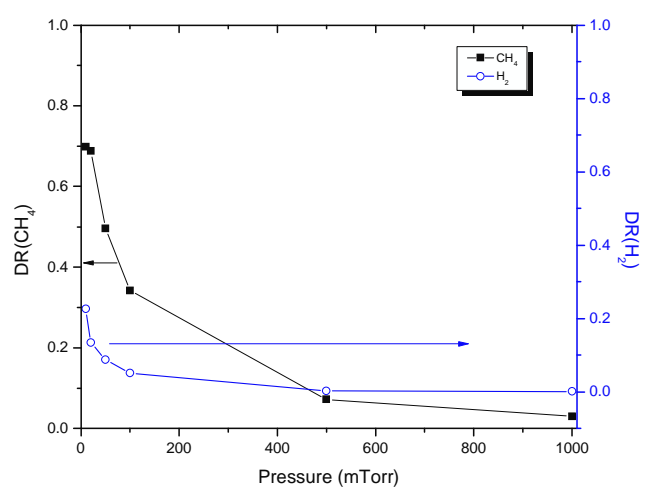

Figure 14 Decomposition rates (DR) of the background gas molecules, calculated for the $\mathrm{CH}_{4} / \mathrm{H}_{2}$ gas mixtures as a function of gas pressure. The other operating conditions are the same as in figure 12 .

\subsection{Effect of bias power}

In the ICP, the power is mainly deposited in the region below the quartz windows, and it decomposes the feedstock gases to create a large number of radicals and ions. Therefore the fluxes of the various species to the substrate are mainly determined by the ICP power, gas pressure, and gas mixture ratios. The bias power is often applied on the substrate in order to grow aligned CNTs/CNTs [7, 16, 44, 48]. Indeed, it was found that local electric fields are built up near the substrate surface, and control the growth direction of CNTs/CNFs $[7,16,44,48]$. Therefore, it is of interest to look in more detail at the DC bias voltage formed in front of the substrate, as well as to the sheath electric field which arises from this DC bias voltage.

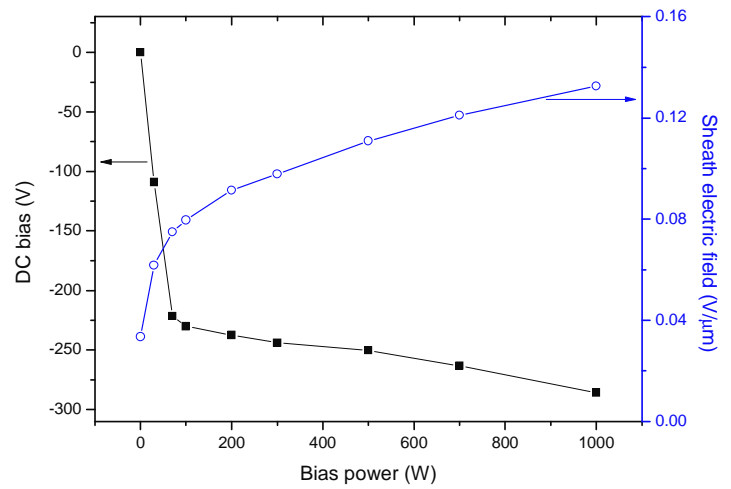

Figure 15 Variation of DC bias (left axis) and sheath electric field (right axis) on the substrate vs. bias power, for a $\mathrm{CH}_{4} / \mathrm{H}_{2}$ gas mixture at a pressure of $50 \mathrm{mTorr}$ with a gas ratio of 20:80. The other operating conditions are the same as in figure 2. 
The DC bias voltage and sheath electric field in front of the substrate surface are plotted as a function of bias power in figure 15 . The bias voltage sharply decreases from 0 to $-230 \mathrm{~V}$ when the bias power changes from 0 to $100 \mathrm{~W}$. When the power is further increased to $1000 \mathrm{~W}$, the change in DC bias voltage is only $56 \mathrm{~V}$ (i.e., until $-286 \mathrm{~V}$ at $1000 \mathrm{~W}$ ). These calculated results are consistent with the observations reported by Lin et al.[20]. Indeed, they found that the RF peak voltage changed from around $300 \mathrm{Vrms}$ to $450 \mathrm{Vrms}$ (corresponding to a bias voltage changing from $-212 \mathrm{~V}$ to $-318 \mathrm{~V}$ ) when the bias power increased from $300 \mathrm{~W}$ to $500 \mathrm{~W}$.

The increase of DC bias voltage as a function of bias power indicates that more energetic ions will bombard the substrate with high bias power. The bombardment of more energetic ions will probably result in a higher surface temperature and hence lead to a higher CNT/CNF growth rate. In addition, the high-energy ions will promote the ion-enhanced etching of amorphous carbon by atomic hydrogen to improve the surface diffusion of carbon on the catalytic nanoparticles. Indeed, Lin et al.[20] reported that the growth rate of CNFs increased significantly with the bias power.

The sheath electric field in front of the substrate changes from $0.034 \mathrm{~V} / \mu \mathrm{m}$ without any bias power to $0.133 \mathrm{~V} / \mu \mathrm{m}$ at a bias power of $1000 \mathrm{~W}$ in our simulation. In [21] it was reported that the sheath electric field is in the range of $\sim 0.01-0.06 \mathrm{~V} / \mu \mathrm{m}$ in an ICP-PECVD system at low pressure of 17 50 mTorr. Somewhat higher values of $\sim 0.1-0.15 \mathrm{~V} / \mu \mathrm{m}$ are reported by Chhowalla[7] and Bower and Zhu[49] for pressures in the order of Torr. These values are consistent with our results, which suggest that the conditions in our study are indeed suitable for CNT/CNF growth. Moreover, the higher electric field in the plasma sheath at higher bias power will probably result in better aligned CNTs/CNFs.

\subsection{Effect of substrate temperature}

It is well known that CNTs/CNFs are typically grown at some elevated temperature of the substrate containing the metal catalysts, in the order of $550^{\circ} \mathrm{C}-800^{\circ} \mathrm{C}[5,11,17]$. Therefore, we want to investigate the effects of the elevated substrate temperature on the plasma chemistry and plasma behavior. In order to calculate the gas temperature distribution, the full momentum equation plus energy equation for all heavy species (neutrals and ions) have been taken into account. The free convection term has been included in the momentum equation, and the inhomogeneous gas density distribution is also taken into account. More details can be found in the review paper of Kushner [38].

As shown in our previous paper[38], the substrate temperature plays a key role in the gas temperature distribution at lower pressures (50 mTorr). The calculated 2D profiles of the gas temperature at a substrate temperature of (a) $0{ }^{\circ} \mathrm{C}$ and (b) $550{ }^{\circ} \mathrm{C}$ are illustrated in figure 16. Note that the reactor walls are kept fixed at a temperature of $324 \mathrm{~K}$ (i.e., $51^{\circ} \mathrm{C}$ ). This value is defined based on typical values used in the semiconductor industry. It is clear that the plasma for the conditions under study is not efficiently heated without substrate heating, because the gas temperature is only about $34 \mathrm{~K}$ higher in the bulk plasma compared to the walls (see figure 16(a)). However, when the substrate is heated to $823 \mathrm{~K}$ (i.e. 550 ${ }^{\circ} \mathrm{C}$ ), the heat transfer towards the bulk plasma is clearly displayed in figure 16(b). The gas temperature gradually changes from $823 \mathrm{~K}$ at the substrate to about $600 \mathrm{~K}$ in the bulk plasma, and reaches $324 \mathrm{~K}$ at the walls.
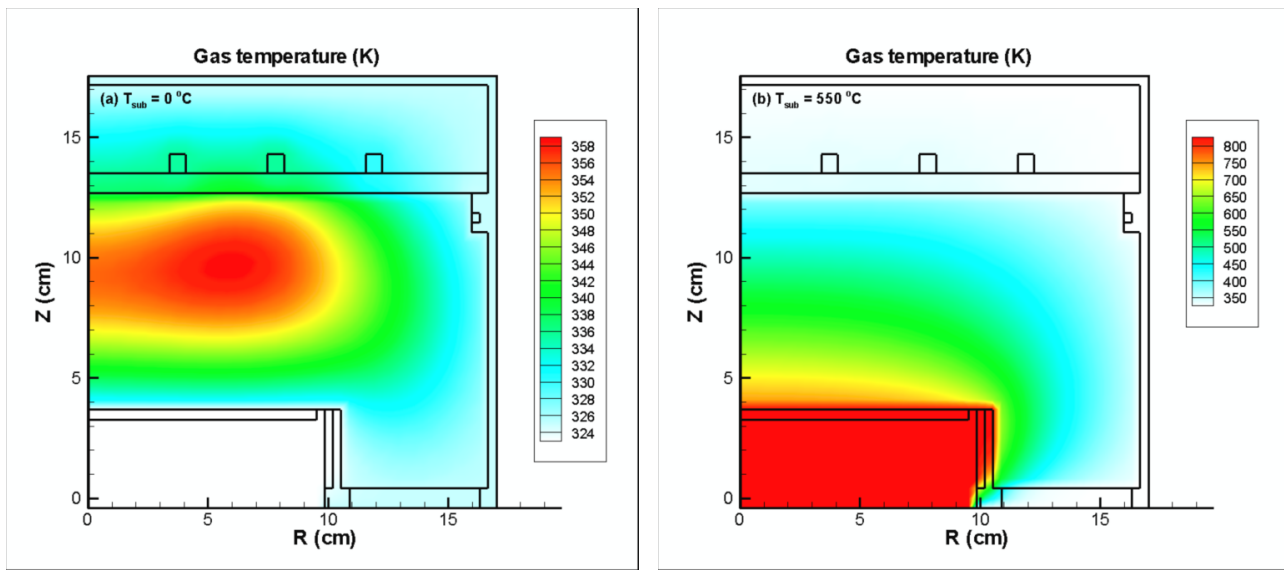
Figure 16 Calculated 2D gas temperature profiles for a $\mathrm{CH}_{4} / \mathrm{H}_{2}$ gas mixture at a pressure of 50 mTorr with a gas ratio of 20:80. The other operating conditions are the same as in figure 2 . The substrate is heated to (a) $0{ }^{\circ} \mathrm{C}$ and (b) $550{ }^{\circ} \mathrm{C}$.

The distribution of gas temperature influences the plasma chemistry in two aspects: First, the reaction rate constants for neutral reactions are often temperature-dependent (see tables in [40]). When the substrate is heated to $823 \mathrm{~K}$ or more, a large temperature difference (several hundred $\mathrm{K}$ ) can be found in the plasma bulk, which will lead to 1-2 orders of magnitude difference in the rate constants. Second, the gradient of gas temperature will push the species to the low-temperature region in order to keep a constant pressure (cf. ideal gas law). Although the first effect will enhance the rate constants for neutral reactions, the lower density of neutrals in the higher temperature region due to the second effect will result in only a slight change in the plasma chemistry.
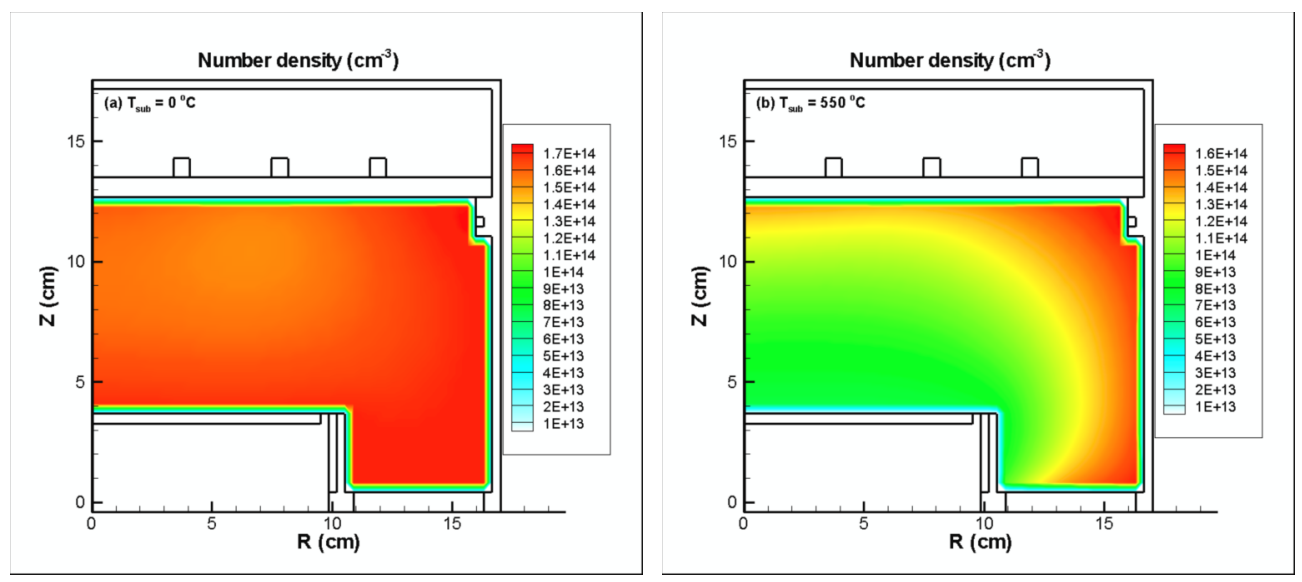

Figure 17 Calculated 2D number density profiles of $\mathrm{CH}_{4}$ at the same conditions as in figure 16.

The calculated 2D number density profiles of $\mathrm{CH}_{4}$ for the substrate temperatures of $0{ }^{\circ} \mathrm{C}$ (a) and $550{ }^{\circ} \mathrm{C}$ (b) are shown in figure 17. As expected from above, a relatively uniform distribution of the $\mathrm{CH}_{4}$ density is observed when the substrate is not heated. On the other hand, when the substrate is heated to $823 \mathrm{~K}$, the $\mathrm{CH}_{4}$ density shows a distribution opposite to the corresponding gas temperature, i.e., the $\mathrm{CH}_{4}$ density exhibits relatively low values in the high temperature region. This indicates that the gradient of gas temperature indeed plays a key role in the species distribution when the substrate is heated, at least for low gas pressure.

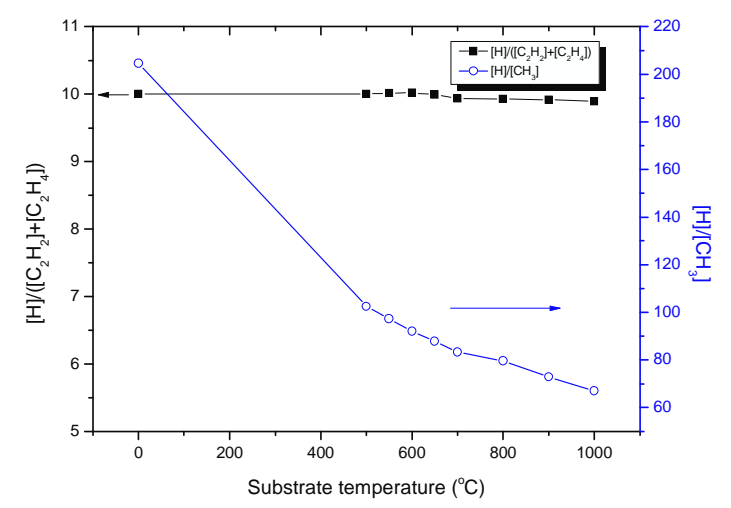

Figure 18 Ratio of etching species $(\mathrm{H})$ to the carbon source for CNTs $\left(\mathrm{C}_{2} \mathrm{H}_{2}+\mathrm{C}_{2} \mathrm{H}_{4}\right)$ and to the carbon source for an amorphous film $(\mathrm{CH})$ as a function of substrate temperature at the same operating conditions as in figure 2.

The ratio of etching species $(\mathrm{H})$ to carbon sources for CNTs $\left(\mathrm{C}_{2} \mathrm{H}_{2}+\mathrm{C}_{2} \mathrm{H}_{4}\right)$ and for an amorphous carbon film $\left(\mathrm{CH}_{3}\right)$ are plotted in figure 18 , as a function of substrate temperature. It is clear that the ratio of $\mathrm{H}$ flux to $\mathrm{CH}_{3}$ flux decreases from 200 for a substrate temperature of $0^{\circ} \mathrm{C}$, to 100 at $550^{\circ} \mathrm{C}$, and further to 60 at $1000^{\circ} \mathrm{C}$, while the ratio of $\mathrm{H}$ flux to $\mathrm{C}_{2} \mathrm{H}_{2}$ and $\mathrm{C}_{2} \mathrm{H}_{4}$ flux remains almost unchanged. This indicates that an amorphous carbon film could be removed more efficiently at a lower substrate temperature. On the other hand, a higher substrate temperature will result in a higher temperature on the catalytic surface, 
which will enhance the carbon diffusion into the particles and increase the surface reaction rate constants, thereby increasing the growth rate of $\mathrm{CNTs} / \mathrm{CNFs}[50]$. Moreover, the DR of the feedstock molecules, $\mathrm{CH}_{4}$ and $\mathrm{H}_{2}$, increase with substrate temperature, as is shown in figure 19. Without substrate heating, the $\mathrm{H}_{2}$ is not decomposed (i.e. a negative value of -0.18 is calculated for the DR, which indicates that there are more $\mathrm{H}_{2}$ molecules formed than decomposed), but the DR increases to 0.2 (i.e. $20 \%$ ) for a substrate temperate of $1000{ }^{\circ} \mathrm{C}$. The DR of $\mathrm{CH}_{4}$ increases almost 2 times (from 0.3 to 0.56 ) when the substrate is heated to $1000{ }^{\circ} \mathrm{C}$, thereby forming other hydrocarbon species, which can react more easily at the catalyst surface, and contribute to CNT/CNF growth. Hence, due to these opposite effects, most probably there will be an intermediate temperature range, which is most suitable for CNT/CNF growth. It is indeed reported in literature $[7,11,12,16,19]$ that a temperature range of $550 \sim 900^{\circ} \mathrm{C}$, is most suitable.

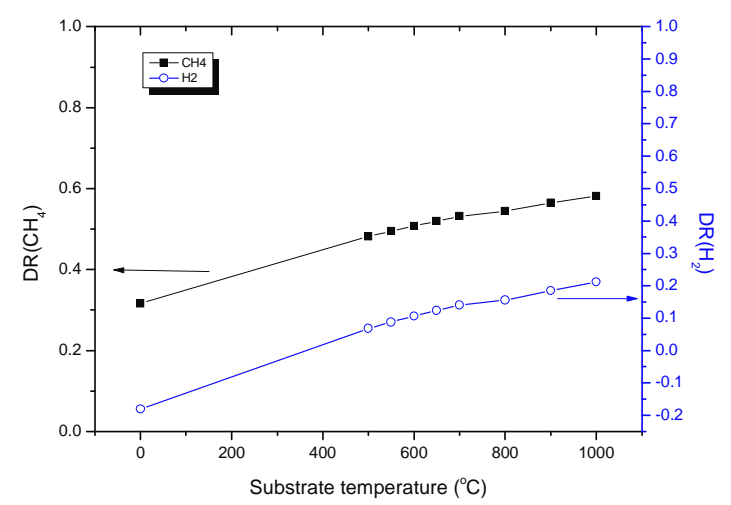

Figure 19 Decomposition rates (DR) of the background gas molecules as a function of substrate temperature for the same conditions as in figure

\section{Conclusions}

An ICP reactor operating under conditions typically used for CNT/CNF growth was investigated by means of hybrid plasma simulations. The influence of processing parameters including gas mixture ratios for four different gas mixtures (i.e., $\mathrm{CH}_{4} / \mathrm{H}_{2}, \mathrm{CH}_{4} / \mathrm{NH}_{3}, \mathrm{C}_{2} \mathrm{H}_{2} / \mathrm{H}_{2}$ and $\mathrm{C}_{2} \mathrm{H}_{2} / \mathrm{NH}_{3}$ ), ICP power, gas pressure, bias power, and substrate temperature on the plasma chemistry is investigated. The fluxes of the various plasma species bombarding the substrate, as well as the decomposition rates (DR) of the feedstock gas molecules, are calculated and analyzed for a large range of process parameters. Furthermore, the ratio of etching species $(\mathrm{H})$ to the carbon source both for CNT/CNF growth $\left(\mathrm{C}_{2} \mathrm{H}_{2}+\right.$ $\left.\mathrm{C}_{2} \mathrm{H}_{4}\right)$ and for amorphous carbon film deposition $\left(\mathrm{CH}_{3}\right)$ is investigated in the same parameter range, because this can give more insight in the conditions for "clean" CNT growth.

In general, it was observed that the fluxes of $\mathrm{C}$ and $\mathrm{C}_{2}$ to the substrate were the lowest of all radicals, which confirms that the carbon source for CNT/CNF growth mainly arises from the decomposition of hydrocarbon molecules on the surface of the catalyst[41].

With respect to the gas mixture ratios, in the $\mathrm{CH}_{4} / \mathrm{H}_{2}$ mixture, a low $\mathrm{CH}_{4}$ fraction (below 20\%) resulted in a high ratio of etching species $(\mathrm{H})$ to growth precursors for CNTs/CNFs $\left(\mathrm{C}_{2} \mathrm{H}_{2}+\mathrm{C}_{2} \mathrm{H}_{4}\right)$ as well as for an amorphous phase $\left(\mathrm{CH}_{3}\right)$. This is expected to result in "clean" conditions for CNT/CNF growth, as the amorphous phase, which might be present in the growing tube, will be etched away by the H-flux and moreover, the carbon supply for CNT/CNF growth is also well controlled. Moreover, the DR of $\mathrm{CH}_{4}$ in the plasma was found to be the highest for a low $\mathrm{CH}_{4}$ fraction, both in the $\mathrm{CH}_{4} / \mathrm{H}_{2}$ and $\mathrm{CH}_{4} / \mathrm{NH}_{3}$ gas mixture, which also points out towards favorable conditions for CNT/CNF growth, as it is generally accepted that $\mathrm{CH}_{4}$ cannot easily decompose at the catalyst surface, in contract to higher hydrocarbons[41].

Similar results were also obtained for the $\mathrm{C}_{2} \mathrm{H}_{2}$-containing gas mixtures. The DR of $\mathrm{C}_{2} \mathrm{H}_{2}$ turns out to drop significantly upon increasing $\mathrm{C}_{2} \mathrm{H}_{2}$ fraction, suggesting a lower CNT/CNF growth rate, because $\mathrm{C}_{2} \mathrm{H}_{2}$ is considered as the main growth precursor. Moreover, the DR of $\mathrm{NH}_{3}$ also drops significantly with increasing $\mathrm{C}_{2} \mathrm{H}_{2}$ fraction, thereby reducing the supply of etching $\mathrm{H}$ species to the growing CNTs. Finally, at higher $\mathrm{C}_{2} \mathrm{H}_{2}$ fraction, there is an excess of heavy hydrocarbon ions, which typically give rise to an amorphous phase. Hence, these calculation results lead us to conclude that an amorphous carbon film 
will be formed at higher $\mathrm{C}_{2} \mathrm{H}_{2}$ fraction, which cannot easily be etched away because of the low amount of etching $\mathrm{H}$ atoms, and this will suppress the growth of CNTs/CNFs.

Therfore, in general it can be concluded that a lower fraction of carbon-supplying gases $\left(\mathrm{CH}_{4}\right.$ and $\left.\mathrm{C}_{2} \mathrm{H}_{2}\right)$ compared to etching gases $\left(\mathrm{H}_{2}\right.$ and $\left.\mathrm{NH}_{3}\right)$ will lead to more "clean" CNT/CNF growth conditions, which is in agreement with literature observations [7, 8, 11, 16, 18, 47].

A higher ICP power will increase the dissociation and ionization of molecules, which results in lower fluxes of the molecules $\left(\mathrm{CH}_{4}, \mathrm{C}_{2} \mathrm{H}_{2}, \mathrm{C}_{2} \mathrm{H}_{4}, \mathrm{C}_{2} \mathrm{H}_{6}, \mathrm{C}_{3} \mathrm{H}_{8}\right.$, and $\left.\mathrm{C}_{4} \mathrm{H}_{10}\right)$, and an increase of the lighter radicals $\left(\mathrm{H}, \mathrm{CH}, \mathrm{C}\right.$, and $\left.\mathrm{C}_{2}\right)$ and ions. The reduction of $\mathrm{CH}_{3}$ and increase of $\mathrm{H}$ radicals at higher ICP power indicates that a relatively "clean" condition for the formation of CNTs/CNFs could be achieved with higher ICP power.

With respect to the gas pressure, the low ratio of $\mathrm{H}$ flux to fluxes of $\mathrm{C}_{2} \mathrm{H}_{2}+\mathrm{C}_{2} \mathrm{H}_{4}$ and the high ratio of $\mathrm{H}$ flux to $\mathrm{CH}_{3}$ flux at pressures above 100 mTorr, in combination with the reduced DR of $\mathrm{CH}_{4}$ indicates that SWCNTs could be synthesized at moderate pressure of around 1 Torr, where the carbon supply for CNTs/CNFs could be well controlled in the $\mathrm{CH}_{4} / \mathrm{H}_{2}$ plasma. This is indeed reported in literature[20]. The DC bias voltage and sheath electric field are calculated for different values of the bias power, and our results are consistent with experimental observations, which indicate that aligned CNTs/CNFs could be grown at the conditions under study. The increase of DC bias voltage with rising bias power indicates that more energetic ions will bombard the substrate, which might result in a higher surface temperature, and consequently in a higher CNT/CNF growth rate. In addition, the high-energy ions will promote the ion-enhanced etching of amorphous carbon film by atomic hydrogen to improve the surface diffusion of carbon on the catalytic nanoparticles. Indeed, Lin et al.[20] reported that the growth rate of CNFs increased significantly with the bias power.

Finally, we investigate the effect of the substrate temperature on the plasma behavior, as CNTs/CNFs are typically grown at elevated substrate temperature [5, 11, 17]. It is found that the substrate temperature influences the distribution of gas temperature, and further affects the profiles of neutral species in the plasma bulk. Indeed, the large gradient of gas temperature drives the species to the low temperature region, which leads to a lower density of species in the region above the substrate where a high gas temperature exists. At higher substrate temperature, the ratio of etching species $(\mathrm{H})$ to the carbon source for an amorphous carbon film $\left(\mathrm{CH}_{3}\right)$ drops, leading to less favorable conditions for clean CNT growth. On the other hand, the surface reaction rates, as well as the DR of $\mathrm{CH}_{4}$, increase with substrate temperature, giving rise to species which can more easily react at the catalyst surface. These two opposite effects will result in an optimum temperature window for CNT/CNF growth, which is indeed reported in literature $[7,11,12,16,19]$ (i.e., in the range of 550 900 ${ }^{\circ} \mathrm{C}$ ).

In summary, we conclude that a lower fraction of hydrocarbon gases $\left(\mathrm{CH}_{4}\right.$ or $\mathrm{C}_{2} \mathrm{H}_{2}$, i.e., below $\left.20 \%\right)$ and hence a higher fraction of etchant gases $\left(\mathrm{H}_{2}\right.$ or $\left.\mathrm{NH}_{3}\right)$ in the gas mixture result in more "clean" conditions for controlled CNT/CNF growth. The same applies to a higher ICP power, a moderate gas pressure above 100 mTorr (at least for SWCNTs), a high bias power (for aligned CNTs), and an intermediate substrate temperature.

\section{Acknowledgements}

We would like to thank the Fund for Scientific Research (FWO Flanders) and the Prime Minister's Office through IUAP-VI for financial support as well as the CalcUA computing facilities of the University of Antwerp for calculation support. We are also very grateful to M. Kushner and group members for providing the HPEM and useful advice. 


\section{References}

[1] Iijima S 1991 Nature 354 56-8.

[2] Tseng G Y and Ellenbogen J C 2001 Science 294 1293-4.

[3] Darkrim F L, Malbrunot P and Tartaglia G P 2002 Int J Hydrogen Energ 27 193-202.

[4] Guillorn M A, Melechko A V, Merkulov V I, Ellis E D, Simpson M L, Baylor L R and Bordonaro G J 2001 J Vac Sci Technol B 19 2598-601.

[5] Meyyappan M 2009 J Phys D Appl Phys 42213001.

[6] Teo K B K, Chhowalla M, Amaratunga G A J, Milne W I, Hasko D G, Pirio G, Legagneux P, Wyczisk F and Pribat D 2001 Appl Phys Lett 79 1534-6.

[7] Chhowalla M, Teo K B K, Ducati C, Rupesinghe N L, Amaratunga G A J, Ferrari A C, Roy D, Robertson J and Milne W I 2001 J Appl Phys 90 5308-17.

[8] Bell M S, Lacerda R G, Teo K B K, Rupesinghe N L, Amaratunga G A J, Milne W I and Chhowalla M 2004 Appl Phys Lett 85 1137-9.

[9] Bell M S, Teo K B K and Milne W I 2007 J Phys D Appl Phys 40 2285-92.

[10] Hash D, Bose D, Govindan T R and Meyyappan M 2003 J Appl Phys 93 6284-90.

[11] Matthews K, Cruden B A, Chen B, Meyyappan M and Delzeit L 2002 J Nanosci Nanotechno 2 475-80.

[12] Wang P, Lu J and Zhou O 2008 Nanotechnology 19 185605-1-7.

[13] Okita A, Suda Y, Ozeki A, Sugawara H, Sakai Y, Oda A and Nakamura J 2006 J Appl Phys 99 0143021-7.

[14] Okita A, Suda Y, Oda A, Nakamura J, Ozeki A, Bhattacharyya K, Sugawara H and Sakai Y 2007 Carbon 45 1518-26.

[15] Oda A, Suda Y and Okita A 2008 Thin Solid Films 516 6570-4.

[16] Delzeit L, McAninch I, Cruden B A, Hash D, Chen B, Han J and Meyyappan M 2002 J Appl Phys 91 6027-33.

[17] Meyyappan M, Delzeit L, Cassell A and Hash D 2003 Plasma Sources Sci T 12 205-16.

[18] Cruden B A and Meyyappan M 2005 J Appl Phys 97 -.

[19] Wei H W 2008 Study of Growth of Vertically-Aligned Carbon Nanofibers by Plasma Enhanced Chemical Vapor Deposition-Growth Mechanism and Field Emission. In: Department of Engineering and System Science, (Hsinchu, Taiwan: National Tsing Hua University) p 175.

[20] Lin Y Y, Wei H W, Leou K C, Lin H, Tung C H, Wei M T, Lin C and Tsai C H 2006 J Vac Sci Technol B 24 97-103.

[21] Wei H W, Leou K C, Wei M T, Lin Y Y and Tsai C H 2005 J Appl Phys 98044313.

[22] Yang C S 2005 Low temperature growth of single-walled carbon nanotubes by PECVD. In: Department of Engineering and System Science, (Hsinchu, Taiwan: National Tsing Hua University) p 88.

[23] Denysenko I B, Xu S, Long J D, Rutkevych P P, Azarenkov N A and Ostrikov K 2004 J Appl Phys 95 2713-24.

[24] Ostrikov K, Yoon H J, Rider A E and Vladimirov S V 2007 Plasma Process Polym 4 27-40.

[25] Denysenko I and Ostrikov K 2007 Appl. Phys. Lett. 90251501.

[26] Levchenko I, Ostrikov K, Mariotti D, and Murphy A B 2008 J. Appl. Phys. 104073308.

[27] Denysenko I and Ostrikov K 2007 Appl. Phys. Lett. 92063108.

[28] Tam E and Ostrikov K 2009 Nanotechnology 20375603.

[29] Lysaght A C and Chiu K S 2008 Nanotechnology 19165607.

[30] Lysaght A C and Chiu K S 2009 Nanotechnology 20115605.

[31] Naha S and Puri I K 2008 J. Phys. D: Appl. Phys. 41065304.

[32] Ventzek P L G, Sommerer T J, Hoekstra R J and Kushner M J 1993 Appl Phys Lett 63 605-7.

[33] Collison W Z and Kushner M J 1996 Appl Phys Lett 68 903-5.

[34] Kushner M J, Collison W Z, Grapperhaus M J, Holland J P and Barnes M S 1996 J Appl Phys 80 133744.

[35] Grapperhaus M J and Kushner M J 1997 J Appl Phys 81 569-77.

[36] Rauf S and Kushner M J 1997 J Appl Phys 81 5966-74.

[37] Kinder R L and Kushner M J 2001 J Vac Sci Technol A 19 76-86.

[38] Kushner M J 2009 J Phys D Appl Phys 42 194013--20.

[39] Cruden B A and Meyyappan M 2005 J Appl Phys 97 084311--15.

[40] Mao M and Bogaerts A 2010 J Phys D Appl Phys 43 205201-1-20.

[41] Hash D B and Meyyappan M 2003 J Appl Phys 93 750-2.

[42] Zhong G, Hofmann S, Yan F, Telg H, Warner J H, Eder D, Thomsen C, Milne W I and Robertson J 2009 J Phys Chem C 113 17321-5.

[43] Shukla B, Saito T, Yumura M and Iijima S 2009 Chem Commun 3422-4.

[44] Hash D B, Bell M S, Teo K B K, Cruden B A, Milne W I and Meyyappan M 2005 Nanotechnology 16 925-30 
[45] Grigonis A, Sablinskas V, Silinskas M and Tribandis D 2004 Vacuum 75 261-7.

[46] Lin C H, Chang H L, Hsu C M, Lo A Y and Kuo C T 2003 Diam Relat Mater 12 1851-7.

[47] Bell M S, Teo K B K, Lacerda R G, Milne W I, Hash D B and Meyyappan M 2006 Pure Appl Chem 78 1117-25.

[48] Maschmann M R, Amama P B, Goyal A, Iqbal Z and Fisher T S 2006 Carbon 44 2758-63.

[49] Bower C, Zhou O, Zhu W, Werder D J and Jin S H 2000 Appl Phys Lett 77 2767-9.

[50] Lee C J, Park J, Huh Y and Lee J Y 2001 Chem Phys Lett 343 33-8. 